\title{
Síndrome de TORCH: enfoque racional del diagnóstico y tratamiento pre y post natal. Recomendaciones del Comité Consultivo de Infecciones Neonatales Sociedad Chilena de Infectología, 2016
}

\author{
Fernanda Cofré, Luis Delpiano, Yenis Labraña, Alejandra Reyes, Alejandra Sandoval y Giannina Izquierdo
}

TORCH syndrome: Rational approach of pre and post natal diagnosis and treatment. Recommendations of the Advisory Committee on Neonatal Infections Sociedad Chilena de Infectología, 2016

There is a lot of bacterial, viral or parasite infections who are able to be transmitted vertically from the mother to the fetus or newborn which implicates an enormous risk for it. The TORCH acronym is used universally to refer to a fetus or newborn which presents clinical features compatible with a vertically acquired infection and allows a rational diagnostic and therapeutic approach. The traditional "TORCH test" is nowadays considered not appropriate and it has been replaced for specific test for specific pathogens under well defined circumstances. The present document reviews the general characteristics, epidemiology, pathogenesis, diagnostic and therapeutic options for the most frequently involved pathogens in the fetus or newborn with TORCH suspicion.

Key words: TORCH, congenital infection, toxoplasmosis, American trypanosomiasis, Chagas disease, congenital rubella syndrome, cytomegalovirus, herpes simplex.

Palabras clave: TORCH, infección congénita, toxoplasmosis, tripanosomiasis americana, enfermedad de Chagas, síndrome de rubéola congénita, citomegalovirus, herpes simplex.

\section{Introducción}

$\mathrm{E}$ xisten numerosas infecciones bacterianas, virales y parasitarias que pueden transmitirse desde la madre al feto o recién nacido $(\mathrm{RN})$ y que representan un riesgo para él. La infección puede ser adquirida en diferentes períodos durante la vida intrauterina y neonatal: in utero, al momento del parto o en período post natal ${ }^{1,2}$. El resultado final de este proceso infeccioso se puede traducir en reabsorción del embrión, aborto, mortinato, malformaciones congénitas, RN prematuros, retardo del crecimiento intrauterino (RCIU), enfermedad aguda in utero en el RN o post parto, infección asintomática pero persistente en el período neonatal con secuelas neurológicas crónicas o un niño sano sin secuelas ${ }^{1,3}$.

El acrónimo TORCH se utiliza en forma universal para caracterizar aquel feto o RN que presenta un cuadro clínico compatible con una infección congénita y permite un enfrentamiento racional, tanto diagnóstico como terapéutico ${ }^{4,5}$. Los microorganismos clásicamente incluidos son Toxoplasma gondii, virus de la rubéola, citomegalovirus (CMV), virus herpes simplex (VHS) y otros agentes (en orden alfabético: enterovirus, Listeria monocytogenes, Mycobacterium tuberculosis, parvovirus B-19, Treponema pallidum, Trypanozoma cruzi, virus de hepatitis B, virus de inmunodeficiencia humana, virus varicela-zoster).

Las manifestaciones clínicas de las infecciones congénitas están influenciadas por múltiples factores independientes entre sí, como el efecto del patógeno sobre la organogénesis, el momento en que ocurre la infección respecto a la edad gestacional, la presencia o ausencia de inmunidad materna y el modo de adquisición de la infección ${ }^{1,5}$. Los abortos o mortinatos generalmente se dan cuando la madre se infecta tempranamente en el embarazo o cuando la enfermedad sistémica de la madre es grave. La razón por la cual se producen partos prematuros no es bien comprendida pero está descrito que aquellos niños con infecciones virales congénitas y pequeños para la edad gestacional (PEG), son el resultado de un RCIU producto de la disminución del número de células de los órganos en desarrollo.

Las infecciones fetales virales pueden sospecharse si la madre se ve expuesta o experimenta una infección por un virus conocido que se puede transmitir en forma vertical o frente a anomalías detectadas en los controles ecográficos de rutina (Tabla 1). El diagnóstico serológico definitivo de infección aguda en la mujer embarazada requiere la demostración de seroconversión ${ }^{1}$.
Santiago, Chile.

Hospital Roberto del Río (FC). Hospital San Borja Arriarán (LD). Hospital San Juan de Dios (YL). Hospital Félix Bulnes (AR). Hospital Sótero del Río (AS) Hospital Exequiel González Cortés (GI).

Los autores declaran no tener conflictos de interés.

No se recibió financiamiento externo para la confección de este manuscrito.

Recibido: 7 de marzo de 2016

Correspondencia a: Fernanda Cofré Segovia fcofre@yahoo.com 
En el RN, los hallazgos clínicos habituales que sugieren una infección congénita aguda son: ictericia, petequias o hepato/esplenomegalia al momento de nacer o inmediatamente posterior al parto, en un neonato habitualmente PEG. Por otro lado, frente a un RN con sospecha de sepsis neonatal en que los cultivos son sistemáticamente negativos para bacterias y hongos, también debe plantearse la posibilidad de una infección congénita aguda (Tabla 2).

Frente a la sospecha de una infección congénita debe evaluarse a la madre en búsqueda de antecedentes que apoyen esta posibilidad. Sin embargo, la ausencia de historia de infección no descarta la posibilidad de infección en el RN, dado que la mayoría de ellas son asintomáticas.

La larga lista de patógenos capaces de producir infecciones congénitas debe ser considerada a la luz de

\section{Tabla 1. Hallazgos ecográficos sugerentes del síndrome TORCH}

Retardo del crecimiento intrauterino

Microcefalia

Ventriculomegalia cerebral o hidrocéfalo

Calcificaciones intracraneales

Cataratas

Cardiomegalia

Insuficiencia cardíaca congestiva

Fuente: Ref. 3 los síntomas clínicos del RN, epidemiología en torno a la gestación, el estado materno de vacunación, el tamizaje serológico efectuado durante el embarazo y factores de riesgo como viajes a zonas endémicas o conductas sexuales. Para que el apoyo con pruebas de laboratorio tenga un buen rendimiento, debe solicitarse muestras adecuadas en el momento correcto y utilizarse exámenes precisos con buena sensibilidad y especificidad ${ }^{4}$. El concepto tradicional de realizar un "test de TORCH" sin consideraciones específicas a cada paciente, hoy en día se considera no adecuado y ha sido reemplazado por exámenes específicos para ciertos patógenos, bajo circunstancias bien definidas.

El ser un RN PEG, condición presente en 3 a $7 \%$ de los RN- no corresponde a una entidad específica en sí, sino que es una manifestación de múltiples patologías maternas, fetales o placentarias. Dado que una de las posibles causas es tener una infección congénita, algunos autores sugieren realizar un "test de TORCH" como parte de la evaluación rutinaria en estos RN; sin embargo, esta asociación está basada en datos limitados. Datos actuales sugieren de poca utilidad un tamizaje TORCH completo a aquellos RN cuya única manifestación clínica es ser PEG, ya que, a manera de ejemplo, la incidencia de CMV estudiada mediante prueba de cultivo acelerado (shell vial) en orina en este grupo específico es tan sólo de $2 \%{ }^{6,7}$.

A continuación revisaremos las características generales, epidemiológicas, patogénicas y principalmente del diagnóstico de los patógenos más frecuentes involucrados en el estudio de pacientes con sospecha del síndrome TORCH.

\begin{tabular}{|c|c|c|c|c|c|c|c|}
\hline & $\begin{array}{c}\text { Toxoplasma } \\
\text { gondii }\end{array}$ & $\begin{array}{l}\text { Virus } \\
\text { rubéola }\end{array}$ & $\begin{array}{l}\text { Citomegalo- } \\
\text { virus }\end{array}$ & $\begin{array}{l}\text { Virus herpes } \\
\text { simplex }\end{array}$ & $\begin{array}{c}\text { Treponema } \\
\text { pallidum }\end{array}$ & $\begin{array}{c}\text { Virus } \\
\text { varicela-zoster }\end{array}$ & $\begin{array}{c}\text { Sepsis } \\
\text { bacteriana }\end{array}$ \\
\hline RCIU & + & + & + & - & - & + & - \\
\hline Erupción, petequias, púrpura & + & + & + & + & + & + & + \\
\hline Ictericia & + & - & + & - & - & - & + \\
\hline Hepato/esplenomegalia & + & + & + & + & + & + & + \\
\hline Microcefalia & + & - & + & + & - & + & - \\
\hline Hidrocefalia & + & + & + & - & - & - & - \\
\hline Calcificaciones intracraneales & + & - & + & + & - & + & - \\
\hline Corioretinitis & + & + & + & + & - & + & - \\
\hline Cataratas & + & + & - & + & - & - & - \\
\hline Hipoacusia & + & + & + & + & - & - & - \\
\hline Cardiopatía congénita & - & + & - & - & - & - & - \\
\hline
\end{tabular}




\section{Toxoplasmosis}

Toxoplasma gondii es un protozoo tisular de distribución cosmopolita, intracelular obligado, del Phylum Apicomplexa.

\section{Epidemiología}

La toxoplasmosis es la zoonosis más frecuente en el mundo, con prevalencia de infección que alcanza hasta $80-90 \%$ en algunos países. Es universal y afecta a todos los animales de sangre caliente incluyendo al hombre. El hombre se infecta al ingerir carne cruda o insuficientemente cocida que tenga quistes del parásito o por el consumo de frutas y hortalizas que estén contaminadas con ooquistes de $T$. gondii que provienen de las heces de gatos jóvenes infectados. En Chile, la infección adquirida comienza al año o año y medio de vida y va aumentando con la edad, de modo tal que $40 \%$ de la población mayor de 21 años presenta la parasitosis ${ }^{8}$.

La toxoplasmosis congénita (TC) es una enfermedad poco frecuente. Sin embargo, sus graves consecuencias en algunos niños hacen que sea motivo de interés y preocupación por parte de obstetras y pediatras. De acuerdo a la experiencia mundial se produce un caso congénito por cada 1.000 partos $^{8}$.

\section{Enfermedad congénita. El riesgo de la transmisión al hijo}

La transmisión del parásito de la madre al hijo puede ocurrir únicamente cuando la infección se adquiere por primera vez durante el embarazo y su frecuencia aumenta gradualmente con el progreso de la gestación. En términos generales, un tercio de las madres con infección aguda darán a luz un hijo con toxoplasmosis, en su mayoría con un desarrollo normal; sin embargo, el 4\% tiene posibilidades de morir, tener un daño neurológico permanente o compromiso visual desde los primeros años de vida ${ }^{9}$.

La infección materna es sub-clínica en la mayoría de los casos; por lo tanto, el diagnóstico se basa en pruebas serológicas. La mujer gestante debe conocer su estado inmunológico con respecto a la infección y las mujeres susceptibles deben tomar las precauciones específicas.
Luego de la primo-infección ocurrida durante el embarazo, puede sobrevenir la transmisión vertical del parásito al producto de la concepción y causar una amplia gama de secuelas que van desde el aborto espontáneo hasta el nacimiento de un niño con diferentes manifestaciones clínicas o asintomático. Sin embargo, la mayoría de los $\mathrm{RN}$ infectados es aparentemente sano y puede presentar las manifestaciones de la infección años después del nacimiento. La transmisión placentaria ocurre en relación lineal con el tiempo de gestación: es baja la frecuencia en el primer trimestre y aumenta hacia el final del embarazo (Tabla 3).

La enfermedad en el hijo se manifiesta en la vida intrauterina o después del nacimiento. El compromiso de quienes presentan la infección varía de acuerdo al grado de lesión: corio-retinitis, ceguera, hidrocefalia, calcificaciones intracerebrales, epilepsia, retraso mental (RM) o retraso del desarrollo psicomotor (RDSM). El riesgo de generar lesiones es mayor en las primeras semanas y poco frecuente después de la semana $26^{9}$.

El riesgo global de transmisión vertical del parásito en la infección materna es alrededor de $40 \%$, pero se reduce significativamente con la administración de espiramicina. En las dos a tres últimas semanas de gestación, el riesgo alcanza a $90 \%$ y no debiera dejar de tratarse.

\section{Manifestaciones clínicas}

Existen cuatro formas de presentación ${ }^{10}$ :

- Enfermedad neonatal: RN gravemente afectado con expresión clínica de una enfermedad generalizada, compromiso del sistema nervioso central (SNC) y con secuelas que no siempre serán modificables con el tratamiento.

- Enfermedad que se manifiesta en los primeros meses de vida: Se incluyen los niños nacidos con enfermedad, aquellos con reconocimiento tardío de la enfermedad independientemente de la gravedad de los síntomas y niños que nacieron asintomáticos y los síntomas se manifestaron tardíamente. El diagnóstico del niño se efectúa meses después del nacimiento. Los signos y síntomas pueden desaparecer con el tratamiento.

$\begin{aligned} & \text { Tabla 3. Riesgo de transmisión y afectación fetal de la toxoplasmosis congénita según el momento del embarazo en que } \\
& \text { se produce la infección }\end{aligned}$
\begin{tabular}{cccc} 
Edad gestacional & Transmisión vertical & Afectación fetal & Tipo de afectación \\
$<14$ semanas & $<10 \%$ & $60 \%$ & Puede ser grave. Lesiones intracraneales y oculares \\
\hline $14-28$ semanas & $15-55 \%$ & $25 \%$ & En general no es grave, lesiones oculares \\
$>28$ semanas & $>55-80 \%$ & $15 \%$ & Excepcional afectación intracraneal, lesiones oculares \\
\hline Ref. 11. & & &
\end{tabular}


- Enfermedad que se manifiesta tarde en la vida: Se diagnostica por la presencia de una secuela o la reactivación de una infección no diagnosticada durante la infancia. Se presenta con frecuencia como corio-retinitis y es menos frecuente con síntomas neurológicos como convulsiones o hidrocefalia por estenosis de un acueducto.

- Infección asintomática: El 90\% de los niños infectados son clínicamente sanos y muestran IgG persistentes o crecientes como única expresión de su infección. Pueden padecer secuelas o desarrollar corio-retinitis, sordera, hidrocefalia, RM o RDSM años más tarde, por lo que requieren tratamiento.

\section{Sintomatología en el recién nacido}

Los signos y síntomas de la TC son muchos y muy variados, pero no específicos (Tabla 4 y Figura 1). También hay que considerar que la TC mantiene una expresión

Figura 1. Toxoplasmosis congénita. clínica semejante con otras infecciones congénitas, especialmente con la infección causada por CMV.

Por su frecuencia y sus características clínicas, las lesiones corio-retinianas y las encefálicas son las más típicas y también, las más graves y deben buscarse en forma dirigida.

\section{Diagnóstico etiológico (Tablas 5 y 6)}

El diagnóstico de la infección por T. gondii está basada primariamente en el estudio serológico.

IgM es lo primero en aparecer, generalmente 1 semana después de la infección, siendo los títulos crecientes hasta 1-3 meses y luego decrecientes a partir de los 9 meses, llegando a la negativización. Un 9-27\% de la población puede tener títulos persistentes de IgM por 2 o más años (Villard).

IgG aparece a partir de las 2 semanas de infección llegando a un peak a los 3 meses, mantiene un plateau por 6 meses y luego de 1 año inicia un lento descenso hasta llegar a su nivel mas bajo que se mantiene de por vida debido a la persistencia de los quistes latentes en el individuo infectado. La avidez de estos anticuerpos IgG aumenta progresivamente durante los primeros 4 meses post infección (Villard).

IgA tiene una cinética de producción similar a IgM, con un peak mas tardío y persistencia de los anticuerpos por 3-4 meses post infección (Villard).

Lo ideal sería realizar el tamizaje sistemático de IgG anti-toxoplasma en toda mujer embarazada en el primer trimestre de gestación. Ante un resultado negativo la mujer embarazada se considera en riesgo de contraer la infección aconsejándose realizar medidas preventivas primarias.

Un resultado positivo puede tener dos interpretaciones:

- Considerar que la IgG específica (+) es debida a una infección previa al embarazo y no realizar otros exámenes o

- Buscar infección reciente mediante detección de IgM; un resultado de IgM negativo indica que la infección fue antes del embarazo y, por tanto, sin riesgo para el feto.

\section{Diagnóstico prenatal}

La detección de IgM materna en la mujer embarazada no significa necesariamente infección aguda, ya que puede persistir más de un año. Ante esta situación se puede realizar exámenes adicionales como determinación del test de avidez y detección de IgA u obtener una segunda muestra de IgG, una vez transcurridas tres semanas, con objeto de ver si se producen diferencias significativas en el título de anticuerpos (Figura 2). La demostración de seroconversión entre dos muestras, separadas por dos a cuatro semanas y obtenidas durante el embarazo, confirma una infección aguda durante la gestación. 


\begin{tabular}{|c|c|c|c|c|}
\hline Diagnóstico & Anticuerpo & Dg prenatal & Dg postnatal & Comentario \\
\hline \multirow[t]{5}{*}{ Serológico } & $\lg G$ & $\begin{array}{l}\text { Negativo: en riesgo } \\
\text { Positivo: protegida } \\
\text { Primo infección: si existe seroconversión } \\
\text { o incremento en } 3 \text { veces el título de lgG } \\
\text { entre dos extracciones en } 3 \text { semanas }\end{array}$ & $\begin{array}{l}\text { Escaso valor. Acs maternos pueden } \\
\text { persistir hasta } 12 \text { meses. } \\
\text { El tratamiento puede retrasar o } \\
\text { anular la síntesis de Acs }\end{array}$ & $\begin{array}{l}\text { Western-blot, permite diferenciar los } \\
\text { Acs maternos de los del RN }\end{array}$ \\
\hline & $\begin{array}{l}\text { IgG avidez } \\
\text { Alta } \geq 30 \% \\
\text { Baja } \leq 20 \% \\
\text { Indeterminada: } \\
\text { entre } 20-30 \%\end{array}$ & $\begin{array}{l}\text { Alta avidez: infección antigua } \\
\text { (más de 3-4 meses) } \\
\text { Baja avidez: infección reciente } \\
\text { (menos de 3-4 meses) } \\
\text { Indeterminada: no valorable }\end{array}$ & Sin interés diagnóstico & $\begin{array}{l}\text { Los rangos pueden variar según los } \\
\text { criterios de la técnica empleada }\end{array}$ \\
\hline & $\lg \mathrm{M}$ & $\begin{array}{l}\text { Escaso valor en la gestante, ya que } \\
\text { puede persistir positiva durante años }\end{array}$ & $\begin{array}{l}\text { Presencia confirma diagnóstico } \\
\text { Presente en } 75 \% \text { de los infectados }\end{array}$ & $\begin{array}{l}\text { La S y E varía según los diferentes test } \\
\text { comerciales }\end{array}$ \\
\hline & $\lg A$ & Puede persistir más de un año & $\begin{array}{l}\text { Presencia confirma diagnóstico } \\
\text { Presente en } 75 \% \text { de los infectados }\end{array}$ & $\begin{array}{l}\text { Detección informativa al combinar } \\
\text { con el resto de lgs }\end{array}$ \\
\hline & $\lg E$ & $\begin{array}{l}\text { Alta E, baja S. } \\
\text { Duración e intensidad variables }\end{array}$ & - & Escasa utilidad diagnóstica \\
\hline
\end{tabular}

Acs: anticuerpos. Igs: inmunoglobulinas. S: sensibilidad. E: especificidad. Ref. 11.

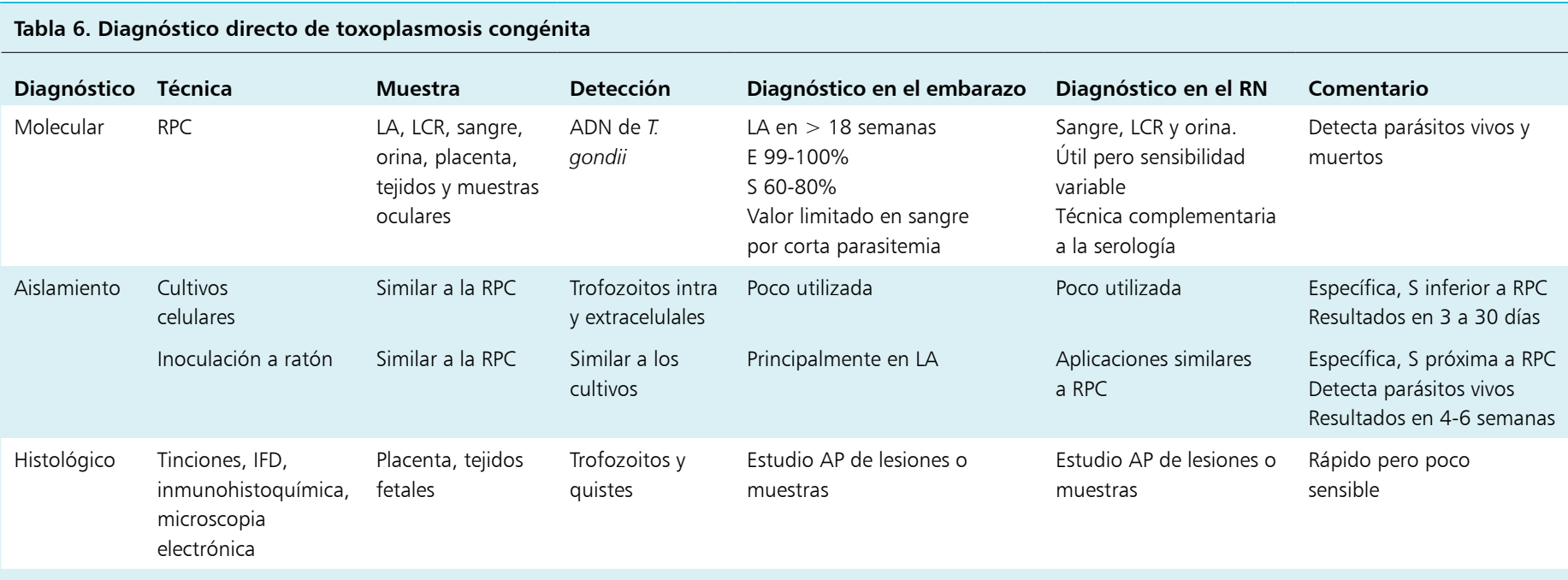

RPC: reacción de polimerasa en cadena. LA: líquido amniótico. LCR: líquido cefalorraquídeo. AP: anatomía patológica. Ref. 11.

Los anticuerpos IgG de alta avidez tardan en aparecer 12 a 16 semanas desde la infección y, por tanto, un resultado de alta avidez en el primer trimestre del embarazo indica que la infección se produjo antes de 16 semanas, por lo que no hay riesgo para el feto. Por el contrario, una baja avidez (o un resultado indeterminado) puede persistir por meses a años después de la infección primaria $y$, por tanto, no debe ser utilizada como única prueba para confirmar una infección reciente.

Los anticuerpos de clase IgA aparecen poco después de los de clase IgM y persisten 6 a 7 meses desde la primo-infección. Sin embargo, se han detectado en algunos casos durante más de un año y su ausencia en un pequeño porcentaje de infecciones agudas, por lo que han de interpretarse junto con los resultados de avidez. Los ensayos de avidez y de IgA son útiles cuando sólo se dispone de una muestra de suero.

Cuando el diagnóstico se plantea en el segundo o tercer trimestre de gestación y no se dispone de una muestra del inicio del embarazo, la serología no nos permite descartar que se haya producido una infección al inicio del embarazo. 


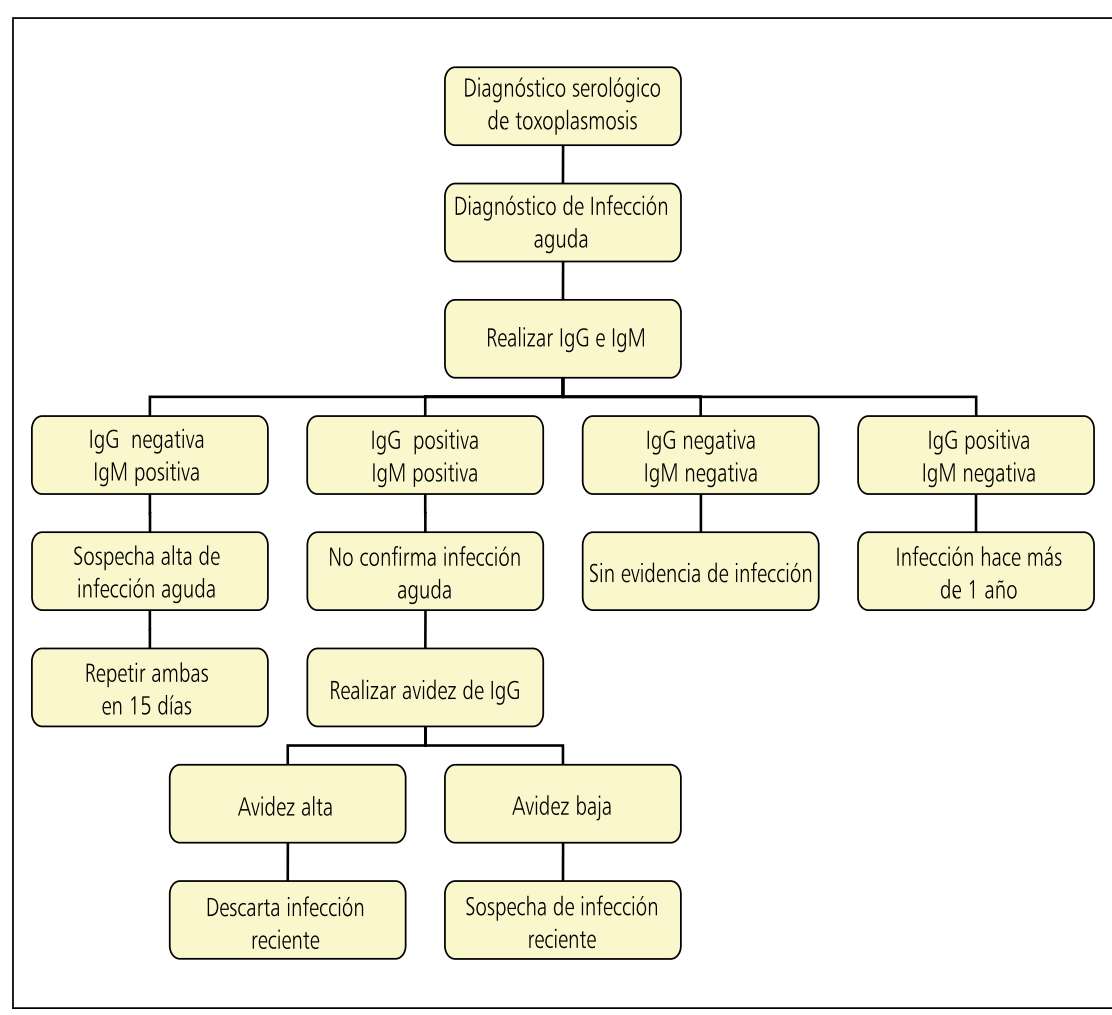

Figura 2. Algoritmo para diagnóstico serológico de infección aguda materna. Ref. 13.

\section{Diagnóstico en el RN}

En el RN la detección de IgM y/o IgA en sangre se considera diagnóstico de infección fetal. La IgM o IgA pueden no ser detectadas hasta en $70 \%$ de los niños infectados en el primer trimestre de gestación, por lo que en estos casos se debe hacer el seguimiento serológico durante el primer año de vida. La desaparición de la $\operatorname{IgG}$ en el primer año de vida descarta la infección.

En el momento del parto se puede realizar estudio con RPC de la placenta lo que traduce la infección de la placenta pero no necesariamente del RN, examen que tiene una especificidad de $97 \%$. El estudio anátomopatológico de la placenta es de baja sensibilidad y se desaconseja ${ }^{11}$.

La RPC en sangre, orina y LCR en el RN se puede realizar como complemento diagnóstico al estudio serológico cuando no se detecta IgA o IgM específicas. Esto último tiene una buena especificidad pero baja sensibilidad, por lo que un resultado positivo confirma la infección pero un resultado negativo no la descarta y requiere de seguimiento serológico ${ }^{11}$.

\section{Estudio complementario del $R \boldsymbol{N}$}

Al RN con TC confirmada o probable deben realizarse estudios analíticos, de imagen y de microbiología.

- Hemograma y evaluación bioquímica completa incluyendo función hepática. Carecen de especificidad y sólo son necesarias para determinar el grado y la extensión de la enfermedad.

El diagnóstico prenatal de infección fetal es necesario cuando los resultados serológicos en la mujer embarazada son indicativos de infección durante la gestación o poco antes de ésta o cuando existe evidencia ecográfica de daño fetal. El diagnóstico de infección fetal se basa en la detección del parásito y/o en la respuesta inmune específica en el feto. La detección del parásito por reacción de polimerasa en cadena (RPC) en muestras de líquido amniótico por amniocentesis es más rápida, sensible y segura que los métodos tradicionales (serología, cultivo e inoculación en ratón) siendo el método de elección. La RPC en líquido amniótico obtenido por amniocentesis a partir de la semana 18 de gestación, tiene una buena sensibilidad y una especificidad de $100 \%$, con un valor predictor positivo de $100 \%$; sin embargo, un resultado negativo no descarta totalmente la infección. La amniocentesis debe realizarse cuando haya trascurrido cuatro semanas desde la infección aguda en la mujer gestante.

La detección del parásito por cultivo en líneas celulares o inoculación en ratón, a partir de muestras de líquido amniótico, también permite establecer el diagnóstico, aunque la menor sensibilidad respecto a la RPC y la mayor complejidad de la técnica hacen que no sea de empleo rutinario.
- Fondoscopia realizada idealmente por un oftalmólogo pediátrico.

- Neuroimágenes: ecografía cerebral o resonancia magnética (RM) cerebral. Una ecografía cerebral realizada por una persona experta puede obviar la RM. Los hallazgos más característicos son las calcificaciones y la hidrocefalia.

- Estudio citoquímico del LCR.

- Estudio microbiológico.

- Obligado: IgM e IgG en la primera semana de vida. Si está disponible, realizar también IgA.

- Recomendado: RPC en sangre, LCR y orina.

- Opcional: estudio de RPC en placenta ${ }^{11}$.

\section{Tratamiento}

Todos los pacientes con TC, independientemente de su condición clínica al nacimiento, deben recibir tratamiento ${ }^{9}$ (Tabla 7).

El seguimiento de cualquier niño con TC debe hacerse hasta pasada la pubertad. Una vez finalizado un año de tratamiento, se debe realizar una fondoscopia, una serología completa y una ecografía cerebral o tomografía computarizada según la historia al nacimiento. 


\begin{tabular}{|c|c|c|c|}
\hline Infección & Tratamiento & Dosis & Duración \\
\hline \multirow[t]{3}{*}{ Infección congénita sintomática } & $P$ & $\begin{array}{l}\text { Inicio: } 1 \mathrm{mg} / \mathrm{kg} / 12 \mathrm{~h} \text {, durante } 48 \text { h posteriormente: } 1 \\
\text { mg/kg/día, hasta los } 6 \text { meses } \\
\text { Del mes } 6 \text { al 12: } 1 \text { mg/kg L-M-V. Dosis máxima: } 25 \text { mg }\end{array}$ & 12 meses \\
\hline & $S$ & 100 mg/kg/día, repartido en dos dosis & 12 meses \\
\hline & $\mathrm{AF}$ & 5-10 mg/3 días por semana & 12 meses y 1 semana \\
\hline $\begin{array}{l}\text { Infección congénita sintomática con } \\
\text { afectación de LCR o corio-retinitis activa } \\
\text { con alteraciones en la visión }\end{array}$ & $\begin{array}{l}P+S+A F \\
\text { Corticoides }\end{array}$ & $\begin{array}{l}\text { Igual que apartado anterior } \\
1 \mathrm{mg} / \mathrm{kg} / \text { día repartido en dos veces al día }\end{array}$ & $\begin{array}{l}\text { Igual que en apartado anterior. } \\
\text { Hasta normalización del LCR o reducción de } \\
\text { la inflamación de la retina }\end{array}$ \\
\hline Infección congénita asintomática & $P+S+A F$ & $\begin{array}{l}\text { Igual que el primer apartado } \\
\text { A partir de los 2-6 meses puede administrarse } \\
\text { pirimetamina días alternos, hasta el mes } 12\end{array}$ & 12 meses \\
\hline Infección dudosa & $P+S+A F$ & Igual que en el primer apartado & $\begin{array}{l}\text { Se mantendrá hasta descartar la infección } \\
\text { (seguimiento de lgG). De confirmarse la } \\
\text { pauta se mantendrá durante } 12 \text { meses }\end{array}$ \\
\hline
\end{tabular}

Si existen signos de curación se hace una fondoscopia cada uno a dos años hasta la pubertad, momento en que el estudio oftalmológico se realiza cada seis meses (por el riesgo de recaída), a pesar de haberse efectuado un tratamiento correcto. Si en ese momento se produce una elevación significativa de $\operatorname{IgG}$, lo que no es habitual, o signos de reactivación de corio-retinitis, se aconseja nuevo tratamiento con pirimetamina más ácido folínico más sulfadiazina durante dos a tres meses ${ }^{14}$.

\section{Prevención primaria; en la mujer embarazada no inmune}

Se deben indicar consejos profilácticos a toda mujer embarazada que presente una serología IgG negativa en la primera visita del embarazo:

- Lavado de manos antes de ingerir alimentos.

- Ingestión de carnes rojas bien cocidas, no consumir carnes ahumadas o en salmuera.

- Lavado minucioso de las manos luego de manipular carne cruda o vegetales frescos.

- Limpieza de las superficies y utensilios de cocina que tuvieron contacto con carne cruda.

- No ingerir vegetales crudos cuando no se pueda asegurar que fueron bien lavados.

- Si realiza trabajos de jardinería, debe usar guantes y luego lavarse las manos.

- Evitar contacto con excretas de gato. En el caso de poseer mascota felina se recomienda remover las excretas diariamente, con guantes y lavado posterior de sus manos, ya que los ooquistes son infectantes a partir de las $36 \mathrm{~h}$ de su eliminación y sobreviven a temperaturas entre $4^{\circ}$ y $37^{\circ} \mathrm{C}^{9}$.

\section{Sífillis}

La sífilis congénita corresponde a la infección transplacentaria producida por Treponema pallidum, desde una madre con sífilis no tratada o inadecuadamente tratada, al producto de la gestación. Esta infección puede afectar al feto en cualquier etapa del embarazo y el riesgo de infección varía según la etapa evolutiva de la enfermedad en la gestante. El daño producido en el feto se relaciona con su capacidad de montar una respuesta inmune, lo que ocurre especialmente después de las 16-20 semanas de gestación.

La infección produce un compromiso multisistémico y es así como las manifestaciones clínicas en el RN infectado son variadas y pueden estar presentes al nacer o desarrollarse en los primeros dos años de vida. Por lo tanto, el diagnóstico de esta patología es complejo y se basa en el análisis de los antecedentes epidemiológicos, serológicos y la clínica del binomio madre-hijo.

\section{Agente causal}

Treponema pallidum es el agente causal, pertenece a la familia Spirochaetaceae, está compuesto por ocho a veinte espiras enrolladas, lo que le permite un movimiento rotatorio. Es una bacteria filiforme que no tiñe con los métodos convencionales (Gram, naranja de acridina, otros). Cuenta con proteínas en su membrana externa que le facilitan la adherencia, atraviesa las membranas y la piel intacta. Es muy lábil a las condiciones ambientales, no se trasmite por la contaminación de objetos, sólo por contacto directo y su reservorio es exclusivamente huma- 
no. Es muy sensible a penicilina, con una concentración inhibitoria mínima (CIM) de $0,018 \mu \mathrm{g} / \mathrm{ml}$ y se multiplica cada 30 a $33 \mathrm{~h}$

\section{Epidemiología}

La Organización Mundial de la Salud (OMS) estima que anualmente hay 12 millones de personas infectadas con sífilis en el mundo, de las cuales 2 millones corresponden a mujeres embarazadas y 270.000 a $\mathrm{RN}$ con sífilis congénita.

En Chile ${ }^{15}$, la tasa de incidencia de sífilis en la población general fue de 22,3 por 100.000 habitantes en el año 2014; 23\% de los casos notificados de sífilis correspondieron a mujeres embarazadas, de las cuales 35 y $34 \%$ cursaron con una sífilis latente precoz y latente tardía, respectivamente, $9 \%$ con sífilis primaria y 5\% sífilis secundaria. La tasa de sífilis congénita confirmada, de acuerdo a criterios epidemiológicos, fue de 0,24-0,25 por $1.000 \mathrm{RN}$ vivos.

Los factores de riesgo materno ${ }^{16}$ relacionados con la infección durante el embarazo son:

- Falta de control del embarazo.

- Abuso de sustancias.

- Antecedentes de otras infecciones de transmisión sexual.

- Comercio sexual.

- Haber recibido tratamiento para la sífilis con antimicrobianos distintos a penicilina benzatina o haberse efectuado este tratamiento antimicrobiano menos de un mes antes del parto.

- Sospecha de re-infección.

- Historia de tratamiento no documentado o verificable.

- Gestantes portadoras de VIH.

- Adolescentes.

- Parejas no tratadas y

- Sífilis diagnosticada en etapa secundaria durante el embarazo.

La principal vía de transmisión es trans-placentaria, si bien se describen casos que la han adquirido por contacto directo con secreciones o lesiones activas ricas en $T$. pallidum, presentes al momento del paso del $\mathrm{RN}$, por el canal del parto. No se transmite por leche materna.

El riesgo de transmisión al producto de la gestación varía según la etapa de la enfermedad en la mujer embarazada; es de $75-95 \%$ en sífilis con menos de un año de evolución (sífilis primaria, secundaria y latente precoz) y de $35-10 \%$ en sífilis con más de un año de evolución (sífilis latente tardía y sífilis terciaria); la situación de mayor riesgo para el feto se produce cuando la mujer embarazada cursa una sífilis secundaria.

La infección no tratada en la mujer embarazada da origen a $25 \%$ de abortos, $25 \%$ de mortinatos y del $50 \%$ restante, $40 \%$ de los RN nacen con sífilis congénita sin- tomática y $60 \%$ nacen asintomáticos, pero desarrollaran la enfermedad en los primeros dos años de vida.

Si la mujer gestante recibe un tratamiento adecuado, antes de las 16-20 semanas de gestación, 100\% de los RN nacen sanos. Si el tratamiento fue posterior a ello se han observado secuelas en 1 a $3 \%$.

La gravedad de la infección se relaciona con el momento en que la mujer embarazada adquiere la infección, la edad gestacional, la carga infectante que afecta al feto $y$ la oportunidad con que la madre establece una respuesta inmune.

\section{Sífilis y embarazo}

La detección de la sífilis a través del tamizaje con serología no treponémica en la mujer embarazada ha demostrado ser una buena estrategia ${ }^{17,18}$, tanto en prevención de la sífilis congénita, como disminuyendo la incidencia de parto prematuro y de muerte fetal y perinatal, por esta causa.

El tamizaje durante el embarazo debe realizarse siempre con técnicas no treponémicas cuantitativas; entre las recomendadas están el RPR y el VDRL. Es recomendable utilizar la misma técnica durante toda la gestación, dado que esto permite evaluar la evolución de la curva serológica, su respuesta al tratamiento y detectar posibles re-infecciones. La confirmación del diagnóstico de la primo-infección en la mujer embarazada se realiza con pruebas serológicas treponémicas (MHA TP-microhemaglutinación de T. pallidum y FTA Abs-fluorescent T. pallidum antibodies). Estas pruebas no son útiles para realizar seguimiento, dado que, en la gran mayoría de los casos, permanecen reactivas durante toda la vida, con posterioridad a la infección. (Nota: Actualmente el Laboratorio de Referencia Nacional del Instituto de Salud Pública-ISP-trabaja con MHA TP). Tanto las pruebas serológicas no treponémicas como las treponémicas detectan IgG, esto es, se produce paso de anticuerpos al feto, a través de la barrera placentaria.

En nuestro país, la normativa del MINSAL establece el tamizaje en la mujer embarazada con pruebas no treponémicas (VDRL o RPR cuantitativo) al momento de la primera consulta, a las 24 semanas, entre las 32-34 semanas de gestación y al parto.

Se ha observado que entre 65 y $85 \%$ de las madres de $\mathrm{RN}$ con sífilis congénita probables y confirmadas, adquieren la infección en el tercer trimestre del embarazo, detectada por seroconversión durante este período o en el parto, o bien, por aumento en la dilución al compararla con las anteriores. Por lo anterior, la situación serológica de la madre siempre debe ser conocida antes de darla de alta desde la maternidad porque esto define en gran medida la conducta a seguir con el RN.

La evolución de la curva serológica de pruebas no treponémicas posteriormente a un tratamiento bien llevado 
en la mujer embarazada, debe evaluarse cuidadosamente, en especial en las mujeres gestantes que han presentado sífilis primaria y secundaria. En un estudio ${ }^{19}$ donde se evaluaron 166 mujeres gestantes con sífilis, con un promedio de edad gestacional de $29 \pm 5$ semanas, de las cuales $56 \%$ presentó sífilis precoz, se observó que sólo en $38 \%$ de ellas disminuyó en dos diluciones la serología no treponémica al parto, y esto se relacionó especialmente con aquellas mujeres que presentaron cuadros de sífilis primaria o secundaria. Si se considera los cuadros de sífilis latente en etapa precoz y tardía, en general, 16 a $28 \%$ de las mujeres embarazadas adecuadamente tratadas no muestran un descenso en dos diluciones de la serología no treponémica, al parto.

Entre los antecedentes epidemiológicos se recomienda verificar la situación serológica y el antecedente de tratamiento de la pareja de la mujer gestante, especialmente cuando hay sospechas de re-infección.

Se han comunicado fracasos de tratamiento en la mujer gestante con sífilis secundaria, a pesar de haber recibido tratamiento adecuado con penicilina benzatina, lo cual guardaría relación con una alta carga infectante; se recomienda en estos casos la evaluación de la unidad feto-placentaria y la búsqueda de indicios de infección fetal.

Se considera tratamiento adecuado de la mujer embarazada, el haber recibido dos dosis de penicilina benzatina de 2.400.000 UI c/u, con un intervalo de una semana, un mes antes del parto, y al parto contar con seguimiento serológico de pruebas no treponémicas que evidencien una disminución de la dilución, en comparación a la dilución al momento del diagnóstico.

Al comparar el uso de una versus dos dosis de penicilina benzatina ${ }^{20}$ en el tratamiento de la mujer gestante, hay estudios que han mostrado una menor eficacia del esquema de una dosis en sífilis secundarias, en sífilis con diluciones de RPR por sobre 1:16 o VDRL de 1:32 o más. Por otra parte, debido a las alteraciones en el volumen de distribución que se produce en la gestación, especialmente en el tercer trimestre, se ha observado ${ }^{21}$ que una dosis de penicilina benzatina de 2.400.000 UI no alcanza concentraciones en el suero materno que aseguren la erradicación de T. pallidum a la semana de su administración.

Ceftriaxona se encuentra entre las opciones de tratamiento de la sífilis en la población general y en la mujer embarazada pero no hay estudios que avalen su eficacia en prevenir la sífilis congénita. En cuanto a los macrólidos/azálidas ${ }^{22}$ como eritromicina y azitromicina, la transferencia placentaria de estos fármacos es baja y las concentraciones alcanzadas en el suero fetal también lo son. Por lo tanto, cualquier tratamiento antimicrobiano recibido por la mujer gestante, diferente a penicilina benzatina, se considera inadecuado y obliga a tratar y estudiar al RN.

\section{Cuadro clínico}

$\mathrm{S} e$ describen dos formas de presentación de la sífilis congénita, la forma precoz, que se manifiesta en los dos primeros años de vida y la forma tardía que se presenta después de esa edad ${ }^{23,24}$.

Las manifestaciones clínicas de la sífilis congénita precoz, va desde la forma multisistémica, oligosintomática a la asintomática, siendo esta última la forma más frecuente.

\section{Forma multisistémica}

Generalmente corresponde a un $\mathrm{RN}$ gravemente enfermo, de aspecto séptico, con RCIU, hepato-esplenomegalia, anemia, trombocitopenia, compromiso del SNC, hepatitis, pancreatitis, neumonía alba, glomerulonefritis, osteocondritis, corio-retinitis en "sal y pimienta", uveítis, lesiones en la piel (Figuras 3 a 5), e incluso, puede cursar

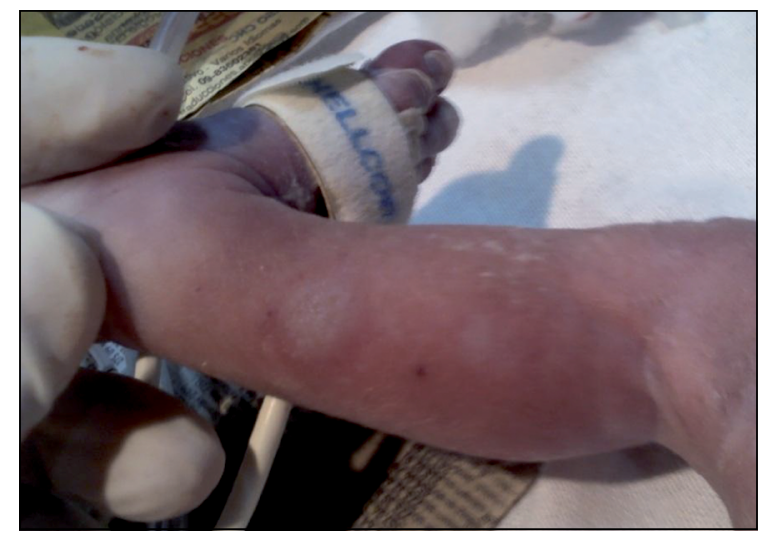

Figura 3. Penfigo sifilítico.

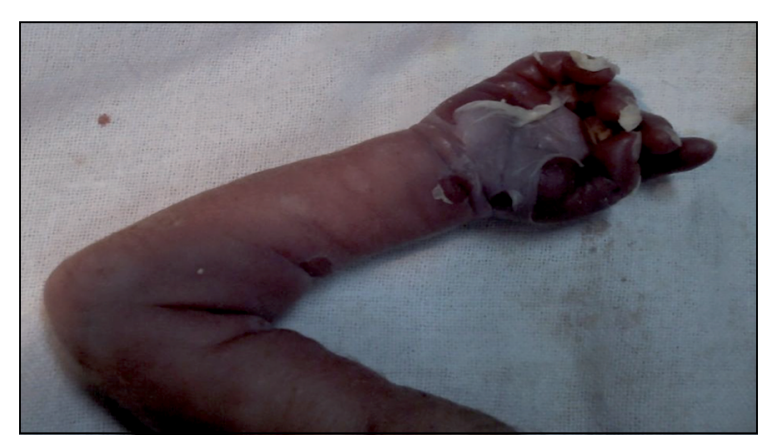

Figura 4. Penfigo sifilítico

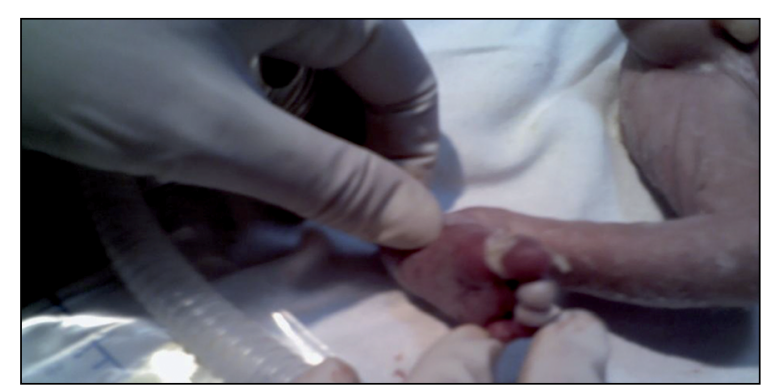

Figura 5. Penfigo sifilítico. 
con un shock séptico. En esta forma clínica, la manifestación más frecuente es la hepato-esplenomegalia, asociada a la presencia de anemia, trombocitopenia, con leucocitosis o leucopenia. La anemia hemolítica se presenta con test de Coombs negativo, se resuelve en forma lenta y puede persistir por semanas; se asocia a formación de complejos inmunes, a crioglobulinemia y macroglobulinemia. La hepatitis ${ }^{25}$ puede ser de tipo colestásica y se resuelve lentamente, al igual que la anemia hemolítica, luego de una terapia adecuada; inicialmente puede apreciarse una exacerbación del cuadro posterior a la administración de penicilina $\mathrm{G}$ sódica. Del punto de vista gastrointestinal, también se describen manifestaciones como ileitis y enterocolitis necrosante.

Diez por ciento de los RN que presentan neumonía alba quedan con daño pulmonar crónico, especialmente prematuros y $\mathrm{RN}$ que requieren ventilación mecánica invasora. Además se asocia a fibrosis obliterante focal.

El diagnóstico se confirma con relativa facilidad ya que, habitualmente cursan con elevadas diluciones de serología no treponémica en el suero.

\section{Forma oligosintomática}

Se presenta generalmente en los primeros seis meses de vida y las manifestaciones clínicas más frecuentes son las lesiones de piel, mucosas y las alteraciones óseas. También pueden presentar, poliadenopatías, síndrome nefrótico, hepatitis y hemoglobinuria paroxística nocturna, entre otras manifestaciones.

Las lesiones cutáneas y mucosas se manifiestan con mayor frecuencia desde la segunda a la décima semana de vida, y pueden ser: exantema máculo-papular simétrico, lesiones descamativas y lesiones ampollares palmo-plantares que corresponden al pénfigo sifilítico. Las manifestaciones de mucosas se presentan con mayor frecuencia entre los 7-10 días de vida y pueden corresponder a: rinitis mucosas, mucopurulenta o sanguinolenta, parches mucosos o placas blanquecinas en la lengua y faringe e incluso laríngeas; estas lesiones son ricas en espiroquetas y, por tanto, infectantes.

Dentro de las manifestaciones óseas se describe la osteocondritis, que origina la pseudoparálisis de Parrot, epifisitis y periostitis, que generalmente se manifiestan después del mes de vida.

\section{Forma asintomática}

Es la más frecuente. Los RN no presentan síntomas ni signos clínicos al nacer, la serología no treponémica es reactiva en similar o menor dilución a la observada en la madre, e incluso puede ser no reactiva, si la infección materna ocurrió muy cercana al parto; por lo tanto, en esta situación el diagnóstico de sospecha se debe establecer con los antecedentes epidemiológicos y serológicos de la madre. El $60 \%$ de los RN infectados nace asintomático y, de no ser tratados, desarrollará la enfermedad en las siguientes tres a ocho semanas de vida.

\section{Neurolúes}

La neurosífilis puede estar presenta en cualquiera de estas formas, habitualmente es asintomática, y en pocos casos se pueden observar alteraciones del citoquímico del líquido cefalorraquídeo. En la era pre-tratamiento con penicilina, $15 \%$ de los RN con sífilis congénita desarrollaban formas meningo-vasculares, con manifestaciones como: meningitis, compromiso de pares craneales, hidrocefalia, infarto cerebral y diabetes insípida. Si bien, las alteraciones en el citoquímico del LCR son infrecuentes, en el RN la presencia de más de 25 leucocitos por $\mathrm{ml}^{17} \mathrm{y} / \mathrm{o}$ proteínas sobre $150 \mathrm{mg} / \mathrm{dL}$ ( $>$ a $170 \mathrm{mg} / \mathrm{dL}$ en prematuros) son sugerentes de una neurosífilis. Cabe señalar que 40 a 50\% de los RN con sífilis sintomática presentan neurosífilis.

El VDRL reactivo en LCR se considera muy específico de neurosífilis aunque cabe la posibilidad de difusión de Ac maternos tipo IgG al suero y LCR del $\mathrm{RN}^{26}$. La detección de material genético, a través de técnicas de RPC en LCR, confirma el diagnóstico de neurosífilis. Las pruebas serológicas treponémicas en el LCR dan falsos positivos, por lo que no se recomiendan para confirmar el diagnóstico de neurosífilis, pero sí tienen un valor predictor negativo.

La sífilis congénita en su forma tardía, es muy poco frecuente y se presenta en los casos de sífilis no tratada. Generalmente se manifiesta en la pubertad y el cuadro clínico es similar a las manifestaciones de la sífilis terciaria del adulto: queratitis intersticial, granulomas necrosantes (gomas), neurosífilis, y la forma cardiovascular. En algunos casos, se pueden evidenciar las secuelas o estigmas, como son: los dientes de Hutchinson, molares "de mora", perforación del paladar duro, nariz "en silla de montar", tibias "en sable", opacidades corneales, atrofia óptica, sordera por compromiso del VIII par craneal e hidrartrosis (articulación de Clutton).

\section{Diagnóstico}

En Chile se ha adoptado, para efectos diagnósticos, la siguiente clasificación epidemiológica ${ }^{10}$ :

\section{Sifilis congénita confirmada}

- Caso en el que se confirma la presencia de T. pallidum en secreciones o tejidos.

- Caso sintomático o asintomático en el que la serología no treponémica (VDRL o RPR) en el suero de sangre periférica del $\mathrm{RN}$ se encuentra $\geq$ dos diluciones (o 4 veces los títulos) por sobre la materna, al momento del parto.

- Caso sintomático o asintomático con VDRL reactivo en LCR del RN. 
- Caso sintomático o asintomático que después del año de vida presenta pruebas serológicas treponémicas reactivas.

\section{Sifilis congénita probable}

Caso en el que se plantea la sospecha clínica de sífilis congénita en base a la evaluación de los antecedentes epidemiológicos, serológicos del binomio madre e hijo y del tratamiento de la madre, y que no cumple con los criterios mencionados previamente, por lo cual no se puede descartar ni confirmar la infección.

Estos criterios difieren de lo establecido por el CDC de Atlanta, E.U.A. ${ }^{27}$, quienes definen como caso confirmado, sólo aquel en quien se logra la identificación del agente causal, en secreciones o tejidos. En el resto de las situaciones mencionadas no sería posible descartar ni confirmar la infección, por lo tanto se mantendrían en una condición de probable.

Para establecer la sospecha diagnóstica de sífilis congénita siempre hay que evaluar:

- Los antecedentes epidemiológicos, serológicos y de tratamiento de la sífilis en la mujer embarazada.

- La situación clínica y la serología en el RN.

La serología no treponémica reactiva al parto, no siempre es sinónimo de sífilis en la mujer gestante, lo ideal es evaluar la curva serológica.

Si en la mujer gestante las pruebas no treponémicas se encuentran reactivas, al momento del parto:

- Hay que verificar si la dilución encontrada corresponde a una seroconversión o se encuentra estable o es más baja o más alta, en comparación a las diluciones previas.

- Preguntar si fue tratada y verificar que el tratamiento haya sido adecuado.

La seroconversión de las pruebas no treponémicas (VDRL-RPR) o un aumento en dos diluciones (o 4 títulos) de la serología en comparación a las diluciones previas al parto, debe llevar a plantear el diagnóstico de sífilis en la mujer embarazada y el de sífilis congénita probable en el $\mathrm{RN}$, independiente de la situación serológica o clínica de éste. La indicación en esta situación es tratar, estudiar y realizar seguimiento al RN, lo que permitirá confirmar el diagnóstico o quedar en condición de probable.

Los VDRL falsamente positivos del embarazo, que habitualmente se presentan con diluciones menores a $1: 4$, se descartan con pruebas treponémicas no reactivas (MHA TP). También se pueden observar falsos negativos; se describen en 1 a los $2 \%$ de los casos de sífilis secundarias y se explican por el fenómeno de prozona (Nota: Prozona $=$ una concentración desproporcionadamente alta de anticuerpos en relación a la de antígeno en la reacción, que inhibe la reacción antígeno-anticuerpo).

En el caso de la mujer gestante, con curva serológica no treponémica reactiva a diluciones estables o menores a las diluciones previas al parto, lo prioritario es establecer si recibió tratamiento adecuado. Si no recibió tratamiento adecuado estaríamos frente a una sífilis congénita probable, independiente de la situación serológica o clínica del RN, y se debe tratar, estudiar y realizar seguimiento.

$\mathrm{Si}$ al momento del parto, la curva serológica de las pruebas no treponémicas (VDRL o RPR) en la mujer gestante, se aprecia estable o reactiva a diluciones más bajas que las previas y con el antecedentes verificable de un tratamiento adecuado durante el embarazo, es necesario evaluar cuidadosamente la serología del RN y sus condiciones clínicas. Lo habitual, es que el RN se encuentre asintomático y que la serología no treponémica en sangre periférica resulte no reactiva o reactiva a diluciones similares o más bajas que la materna, lo que permite realizar seguimiento del RN y así, verificar la negativización del VDRL o RPR; esto ocurrirá, generalmente, antes de los tres meses de vida, dado que esta serología reactiva corresponde a un paso trans-placentario de anticuerpos tipo IgG maternos.

Todo RN hijo de madre con serología no treponémica reactiva al parto debe realizarse serología no treponémica en sangre periférica (nunca del cordón umbilical). Un VDRL o RPR reactivo en el RN, por sobre dos diluciones (ó 4 títulos) a la observada en la madre, confirma el diagnóstico, pero la ausencia de este criterio no descarta la infección. El VDRL reactivo en LCR es muy sugerente de neurosífilis en presencia o ausencia de manifestaciones clínicas en el RN, examen que tiene una sensibilidad y especificidad de 90 y 53\%, respectivamente.

La forma clínica multisistémica, si bien es poco frecuente, habitualmente se asocia a diluciones de VDRL o RPR en suero o sangre más elevadas.

La detección en el RN asintomático o sintomático, hijo de madre no tratada o inadecuadamente tratada, con pruebas no treponémicas (VDRL-RPR) en diluciones dos veces menores en relación a la serología materna, no permite confirmar la infección congénita. Estos casos quedan catalogados como probables y es posible que el seguimiento permita confirmar el diagnóstico con pruebas treponémicas reactivas después del año de vida, y en caso contrario quedan en la condición de probables.

El hallazgo de test serológico treponémicos y no treponémicos (VDRL o RPR) reactivos en el RN puede corresponder al paso trans-placentario de IgG materna pero la determinación de IgM específica para T. pallidum en el RN es signo sugerente de infección congénita. Está presente en 80 y $35 \%$ de los RN sintomáticos y asintomáticos, respectivamente, con una sensibilidad de 
$66 \%$ y especificidad de $100 \%$. Tiene valor diagnóstico sólo cuando la madre ha sido inadecuadamente tratada o no ha recibido tratamiento para la sífilis; por otra parte, cuando no se detecta, ello no descarta la infección del RN.

La determinación de pruebas treponémicas en el RN no se recomienda, mide IgG (paso trasplacentario), y no aporta al diagnóstico de sífilis congénita.

La determinación de material genético a través de estudios de RPC se ha realizado en suero o sangre del RN con una sensibilidad y especificidad de 94,90 y $97 \%$, respectivamente y en LCR con una sensibilidad de $65 \%$ y especificidad de $97 \%$.

Hasta el momento no se dispone de un método diagnóstico único con la suficiente sensibilidad y especificidad que permita descartar la infección en el RN.

\section{Manejo \\ Se pueden presentar dos situaciones ${ }^{10}$ : \\ $R N$ hijo de madre con sifilis sin tratamiento o inadecuadamente tratada o con reinfección}

El RN se debe tratar y estudiar. El estudio básico recomendado, tanto en el $\mathrm{RN}$ sintomático como asintomático, incluye VDRL en sangre o suero periférico, punción lumbar para estudio citoquímico y VDRL del LCR, radiografía de huesos largos y cráneo, fondoscopia, hemograma con recuento de plaquetas, pruebas de función hepática. En pacientes sintomáticos se debe completar el estudio con radiografía de tórax, evaluación de la función renal y otros exámenes, de acuerdo a la sintomatología y nivel de gravedad de cada caso.

\section{$R N$ hijo de madre con sifilis adecuadamente tratada}

En estos RN no se recomienda realizar estudio ni hospitalizar, pero sí es necesario determinar el VDRL o RPR en sangre periférica para establecer su condición serológica basal. Si la prueba serológica no treponémica en el $\mathrm{RN}$ resulta no reactiva o reactiva a una dilución menor o igual a la observada en la madre al momento del parto, al paciente sólo se le realiza seguimiento del VDRL o RPR hasta verificar su negativización.

En un seguimiento de $121 \mathrm{RN}$ hijos de madres con sífilis adecuadamente tratadas, 95\% de los casos negativi-

\begin{tabular}{|lclll}
\hline \multicolumn{4}{l}{ Tabla 8. Tratamiento del RN con sífilis congénita } \\
\hline Edad & Dosis de penicilina G & Vía & Frecuencia & Duración \\
0-7 días & $50.000 \mathrm{UI} / \mathrm{kg} /$ dosis & ev & $\mathrm{c} / 12 \mathrm{~h}$ & 10 días \\
8-28 días & $50.000 \mathrm{UI} / \mathrm{kg} /$ dosis & ev & $\mathrm{c} / 8 \mathrm{~h}$ & 10 días \\
$>28$ días & $50.000 \mathrm{UI} / \mathrm{kg} /$ dosis & ev & $c / 406 \mathrm{~h}$ & 10 días \\
\hline Ref: Rev. Chilena Infectol 2013; 30 (3): 259-302.
\end{tabular}

zaron el VDRL antes de los tres meses de vida y $100 \%$ a los cuatro meses ${ }^{30}$; en todos ellos las pruebas treponémicas realizadas después del año de vida fueron no reactivas, lo que permitió descartar la infección en $100 \%$ de los casos. No hay evidencia científica, más allá de la opinión de algunos expertos, que avale el uso de penicilina benzatina en este grupo de $\mathrm{RN}$ en forma profiláctica; en este aspecto no hay consenso en las guías internacionales ${ }^{28}$.

Entre las reacciones adversas no alérgicas ${ }^{29}$ de penicilina benzatina, se describen las vasculares con una frecuencia de $42 \%$. Cincuenta por ciento de ellas se presentaron en niños menores de 5 años, con $6 \%$ de gangrena o necrosis y en 3\% de amputación de la extremidad afectada. En Chile no se recomienda el uso de penicilina benzatina bajo 2 años de edad, por el riesgo de lesiones vasculares (síndrome de Nicolau) que se presentan por la administración de este antimicrobiano en forma accidental endovascular, pero que también se describen secundariamente a un fenómeno inflamatorio desencadenado en los tejidos circundantes a los vasos sanguíneos, sin que necesariamente se haya administrado directamente en el torrente sanguíneo.

Si la prueba serológica no treponémica en el $\mathrm{RN}$ resulta reactiva a una o más diluciones por sobre la observada en la madre al momento del parto, el RN se debe tratar y estudiar. Esto se observa en madres que se reinfectan o cuando se produce un fracaso del adecuado tratamiento con penicilina benzatina, en la mujer embarazada, lo cual si bien, es muy infrecuente, se asocia con la co-existencia de infección por VIH y con sífilis secundaria.

\section{Tratamiento}

El tratamiento de elección para la sífilis congénita y la neurosífilis es penicilina $\mathrm{G}$ sódica. Actualmente se recomienda 10 días de tratamiento con penicilina $\mathrm{G}$ sódica en los caso de sífilis congénita con y sin neurosífilis ${ }^{10}$ (Tabla 8).

La penicilina procaína, de administración intramuscular no alcanza concentraciones adecuadas en el SNC, que aseguren la erradicación de T. pallidum. No hay evidencia que avale el uso de otros $\beta$-lactámicos ni tampoco de otros antimicrobianos para el tratamiento de la sífilis congénita.

\section{Seguimiento}

El seguimiento clínico y serológico permite verificar la negativización de las pruebas serológicas no treponémicas (VDRL, RPR) en suero y en los casos de neurosífilis en el LCR, lo que asociado a una buena evolución clínica da cuenta del éxito del tratamiento.

La determinación de pruebas treponémicas después del año de vida, permite confirmar algunos casos, pero no están recomendadas para realizar el seguimiento serológico.

El diagnóstico y seguimiento serológico debe realizarse siempre con la misma técnica no treponémica, dado 
que las diluciones obtenidas por las diferentes técnicas no son comparables entre ellas.

Se diferencian tres situaciones específicas:

$R N$ hijos de madres con sifilis adecuadamente tratadas

En estos casos se realiza control médico y de la serología no treponémica, mensualmente, hasta su negativización, que habitualmente ocurre antes de los cuatro meses de vida.

\section{$R N$ con sifilis congénita probable y sifilis confirmada}

Se recomienda realizar control clínico y con serología no treponémica (VDRL, RPR) al mes, 2, 3, 6 y 12 meses de edad. Si el VDRL o RPR permanece reactivo a los seis meses de vida se debe estudiar al paciente y evaluar la necesidad de repetir el tratamiento. Después de los 12 meses se realizan pruebas treponémicas, que, en los casos de sífilis probables, permitiría confirmar la infección. En los casos sintomáticos las pruebas treponémicas pueden permanecer reactivas durante toda la vida.

\section{$R N$ con neurosifilis}

Además realizar el seguimiento correspondiente a una sífilis confirmada, se debe determinar el VDRL en LCR a los seis meses de vida, para verificar su negativización. La presencia de celularidad, aumento de las proteínas y/o VDRL reactivo en LCR a los seis meses de vida, es indicación de repetir el tratamiento. En estos pacientes se recomienda realizar seguimiento neurológico, oftalmológico y por otorrinolaringólogo.

Los pacientes con diagnóstico de sífilis congénita sintomática confirmada negativizan el VDRL o RPR en suero o sangre más tardíamente que los casos asintomáticos, lo cual ocurre habitualmente alrededor de los seis meses de vida. Se describen casos en que la negativización ha sido más tardía pero se asocia a diluciones iniciales de VDRL o RPR muy elevadas y amerita un seguimiento cuidadoso; ante la duda de fracaso de tratamiento se recomienda evaluar y tratar nuevamente.

En general, los casos con persistencia del VDRL en LCR o en suero reactivo, después de los seis meses de vida, tienen indicación de evaluación y considerar repetir el tratamiento.

\section{Enfermedad de Chagas (Tripanosomiasis americana)}

La enfermedad de Chagas es una zoonosis parasitaria causada por Trypanozoma cruzi, cuyo vector es Triatoma infestans ("vinchuca") y es endémica en 21 países de Latinoamérica, incluido Chile, perteneciendo al grupo de las enfermedades olvidadas ("neglected diseases" en inglés), según conceptos acuñados por la $\mathrm{OMS}^{31-33}$. El parásito se transmite a través de: deposiciones de un triatoma infectado (vectorial), transfusiones de sangre o de órganos sólidos (transfusional), trans-placentaria o ingestión oral de alimentos o líquidos contaminados $(\text { alimentaria })^{31}$.

\section{Epidemiología}

En zonas no endémicas, la transmisión congénita o trans-placentaria es el principal modo de transmisión de T. cruzi $^{34}$. La tasa de transmisión congénita reportada en Latinoamérica varía de $0,7-18,2 \%$, con un promedio de $5 \%$ en áreas endémicas ${ }^{31,34}$.

La enfermedad de Chagas congénita puede presentarse en las fases aguda y crónica de la infección materna, puede repetirse en cada embarazo y transmitirse desde una generación a otra (vertical) pero, generalmente se da en el contexto de una madre seropositiva que se encuentra en la fase crónica indeterminada o asintomática de la enfermedad ${ }^{34,35}$

\section{Infección vertical}

La infección crónica materna no tiene efecto en el destino del embarazo o del RN si no existe transmisión al feto. Cuando el feto resulta infectado hay un aumento del riesgo de parto prematuro, bajo peso de nacimiento y rotura prematura de membranas, producto de la inflamación placentaria ${ }^{36}$. Durante el primer trimestre del embarazo la transmisión es probablemente inhabitual y ocurre con mayor frecuencia durante el segundo o tercer trimestre del embarazo, cuando el flujo sanguíneo placentario se hace continuo y difuso, facilitando el intercambio sanguíneo feto-placentario ${ }^{36}$. Sin embargo, como la mayoría de las mujeres se infectan antes de comenzar el embarazo, es imposible determinar el momento exacto de la transmisión del parásito ${ }^{36}$.

Los factores de riesgo para la transmisión congénita son:

- Madres que viven o han migrado de zonas endémicas.

- Madres que viven o han migrados de áreas con altas tasas de transmisión.

- Antecedente de hermanos con infección congénita.

- Madre con parasitemias detectables (RPC en sangre positiva)

- Madres con disminución de la respuesta inmune mediada por células $\mathrm{T}$.

- Co-infección materna con VIH o malaria ${ }^{36}$.

\section{Cuadro clínico}

La mayoría de los RN son asintomáticos (40$100 \%)^{35-37}$. Los signos y síntomas clínicos son inespecíficos y comunes a otras infecciones congénitas encontrándose frecuentemente prematurez, bajo peso de nacimiento y RCIU. Puede haber distress respiratorio 


\begin{tabular}{|}
$\begin{array}{l}\text { Tabla 9. Elementos clínicos para la sospecha de enferme- } \\
\text { dad de Chagas congénita sintomática }\end{array}$ \\
\hline Signos y síntomas de infección congénita: \\
Prematurez \\
Pequeño para la edad gestacional \\
Apgar bajo \\
Síndrome de distress respiratorio \\
Hepato/esplenomegalia \\
Ictericia \\
Madres seropositiva para T. cruzi \\
Hermano con enfermedad de Chagas congénita \\
Evidencia de miocarditis o meningoencefalitis \\
\hline Adaptado de Ref. 36.
\end{tabular}

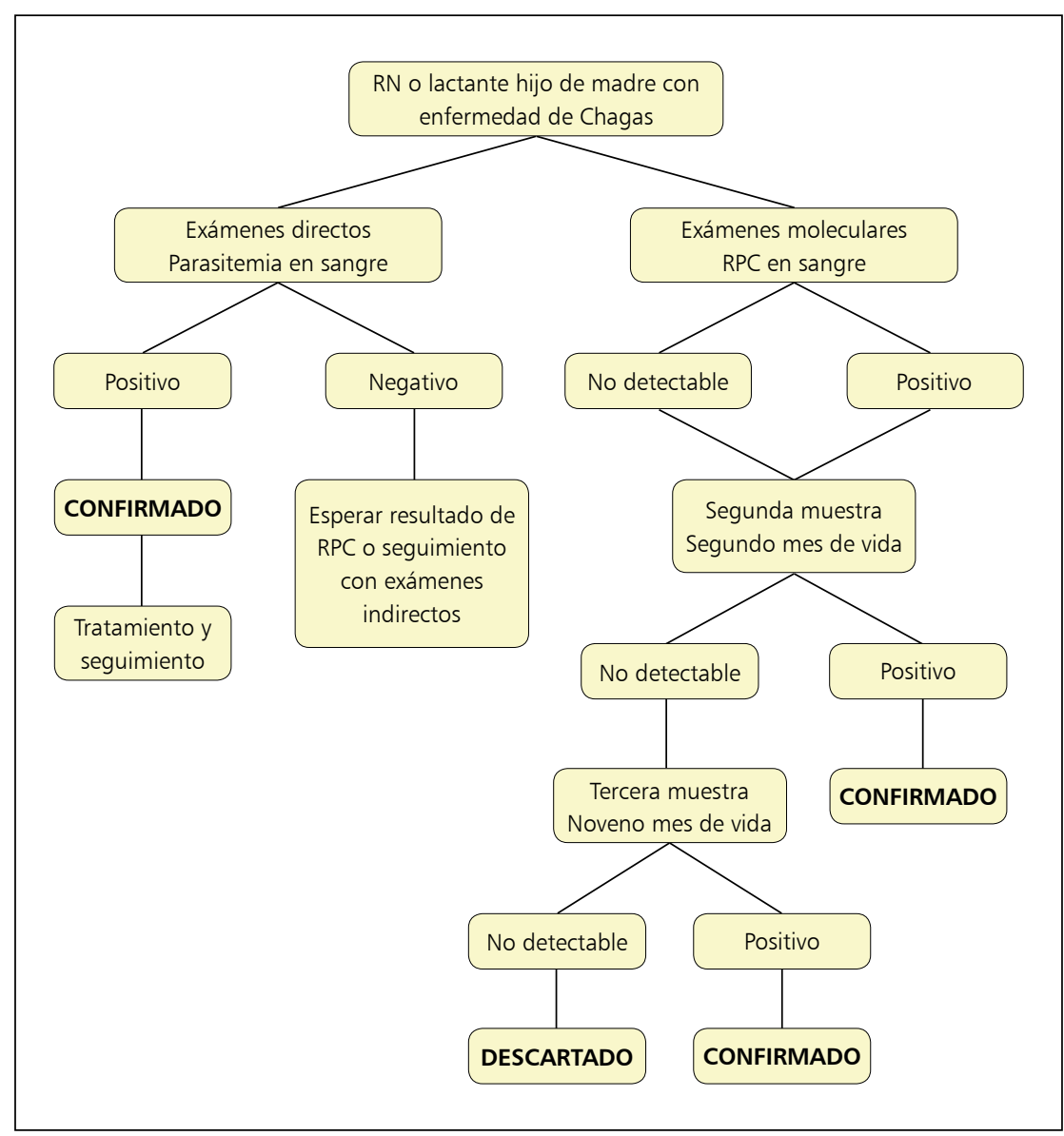

Figura 6. Algoritmo diagnóstico de infección congénita en el recién nacido hijo de madre con enfermedad de Chagas. Ref. 33. por neumonitis parasitaria y son frecuentes la ictericia, hepatomegalia y esplenomegalia ${ }^{36,37}$.

Se considera sospechoso de enfermedad de Chagas congénita aquel RN hijo de madre infectada que presenta convulsiones, hepato-esplenomegalia, cardiomegalia, distress respiratorio, hidrops fetal, prematurez, o que es asintomático pero con antecedentes maternos de la enfermedad ${ }^{32,33,35-37}$ (Tabla 9). La mortalidad de la infección congénita es de $5 \%$ y está dada principalmente por miocarditis y meningo-encefalitis lo que se asocia a altas parasitemias en el $\mathrm{RN}^{34,36}$.

\section{Diagnóstico}

El diagnostico de infección en la madre se realiza por serología mediante IF y/o ELISA y se recomienda en toda mujer embarazada: residente en zonas endémicas, residente en zonas no endémicas y que han recibido transfusiones de sangre en zonas endémicas, residentes en zonas no endémicas y que han nacido o vivido en zonas endémicas o cuya madre haya nacido en zonas endémicas ${ }^{35,36}$. Dado que en nuestro país la presencia del $T$. infestans es endémica desde la Región de Arica-Parinacota (extremo norte) hasta la Región del Libertador Bernardo O'Higgins (VII Región, territorio central) a partir del año 2011 se recomienda el tamizaje serológico con $\operatorname{IgG}$ a todas las mujeres embarazadas en su primer control prenatal ${ }^{32,33}$.

El aclaramiento de anticuerpos maternos se produce entre los 8 y 12 meses de vida por lo que la serología convencional (métodos indirectos) no permite hacer el diagnóstico precoz de infección congénita pero sí permite hacer diagnóstico de infección congénita en lactantes sobre 8 meses y permite descartar la infección congénita en lactantes bajo 8 meses $^{31,35-37}$. El diagnóstico en el RN se hace por la demostración de la parasitemia mediante métodos directos (parasitemia en sangre) y moleculares (RPC en sangre); lactantes bajo 9 meses de vida requieren dos RPC (+) para la confirmación diagnóstica ${ }^{32,33,35,36}$. Si bien una RPC positiva durante los primeros 12 meses de vida es diagnóstica de infección, es esencial el seguimiento serológico cuando la RPC es negativa, dado que no necesariamente traduce la ausencia del parásito ${ }^{31}$ (Figura 6). A nivel internacional la técnica de RPC para el diagnóstico de infección congénita en el $\mathrm{RN}$ esta aún bajo evaluación por la OMS y no ha sido recomendado su uso $^{35}$ dado las dificultades técnicas en su implementación en forma masiva y que la presencia de $\mathrm{ADN}$ del parasito en la sangre del $\mathrm{RN}$ no traduce necesariamente una infección activa ni que el parasito sea viable sino que puede ser producto de una transferencia transplacentaria ${ }^{36,37}$.

La infección congénita se considera frente a:

- Un RN hijo de una madre infectada (serología o RPC en sangre positiva para T. cruzi).

- Un RN en que se logra identificar el T. cruzi al momento de nacer. 
- Un lactante con serología o RPC positiva para T. cruzi de origen no materno identificado luego del período de $\mathrm{RN}$ en que se ha descartado la transmisión por vectores y/o transfusión sanguínea ${ }^{35}$.

Ante todo diagnóstico confirmado de enfermedad de Chagas, sintomático o asintomático, de la madre y/o el $\mathrm{RN}$, debe realizarse la notificación ENO (Enfermedades de Notificación Obligatoria) según lo establecido por la normativa del MINSAL de Chile ${ }^{32,33}$.

\section{Tratamiento}

Una vez hecho el diagnóstico, el inicio del tratamiento debe ser inmediato con benznidazol o nifurtimox; en Chile sólo existe disponibilidad de nifurtimox. Si bien no existen estudios randomizados, la experiencia clínica indica que ambos fármacos son igualmente efectivos ${ }^{35}$. La dosis recomendada de benznidazol en niños y adultos es de $5-7 \mathrm{mg} / \mathrm{kg} /$ día y en $\mathrm{RN}$ y hasta 1 año de edad pueden usarse dosis de $10 \mathrm{mg} / \mathrm{kg} /$ día. La dosis recomendada de nifurtimox en $\mathrm{RN}$ y niños es de $10-15 \mathrm{mg} / \mathrm{kg} /$ día. La duración del tratamiento recomendada es de 60 días y no menos de 30 días $^{32,33,36,37}$.

El tratamiento generalmente es exitoso y sin las reacciones adversas de los adultos si se realiza en el primer año de vida $^{32,33,35}$, llegando hasta $100 \%$ de efectividad ${ }^{31,34,37}$. La curación se demuestra por la negativización de la serología y la RPC ${ }^{31,37}$. Murcia y cols., demostraron la negativización de la RPC al mismo tiempo que la serología, lo que probablemente traduce la efectividad del tratamiento en eliminar el parásito ${ }^{31}$.

Aunque el tratamiento de las madres crónicamente infectadas no garantiza su cura, la posibilidad de infección congénita sí disminuye tratando a las mujeres seropositivas en edad fértil previamente al embarazo ${ }^{31,37}$. Para aquellas mujeres embarazadas e infectadas por $T$. cruzi no existen medidas específicas o directas que prevengan la infección congénita, dado que no se recomienda el tratamiento antiparasitario durante el embarazo por su efecto teratogénico ${ }^{35,37}$. La suspensión de la lactancia en madres infectadas no está recomendada como medida de prevención de la infección congénita ${ }^{32,33,36}$ y sí se recomienda el estudio sistemático de los hermanos y parientes que conviven con la madre infectada mediante serología $a^{32,33,35,37}$.

\section{Rubéola}

Enfermedad exantemática clásica de la infancia e inmunoprevenible, que tiene como único reservorio al ser humano. Este virus ARN (una hebra de polaridad positiva) pertenece a la familia Togaviridae, al género Rubivirus y es el único exponente de este género con sólo un serotipo, pudiendo diferenciarse diversos genotipos. Posee tres polipéptidos estructurales: las glicoproteínas E1, E2 y proteína de la cápside $\mathrm{C}$, además de otras proteínas no estructurales que participan en la replicación y transcripción. Se transmite por vía respiratoria a través de gotitas, contacto y por vía trans-placentaria ${ }^{38}$.

\section{Epidemiología}

$\mathrm{Su}$ mayor relevancia en salud pública obedece a su participación etiológica en el síndrome de rubéola congénita (SRC) (Tabla 10). Éste se produce cuando el virus

Tabla 10. Definición de caso de síndrome de rubéola congénita según OMS

\section{Caso sospechoso}

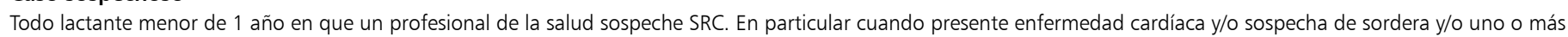

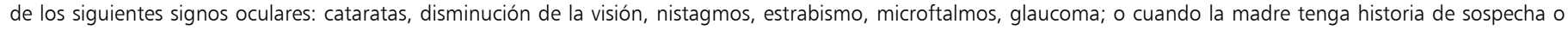
confirmación de rubéola durante el embarazo, aún con RN sin signos de este síndrome

\section{Caso confirmado}

Lactante con diagnóstico de dos complicaciones especificadas en A o una de sección A y una de sección B:

A: cataratas, glaucoma congénito, cardiopatía congénita, hipoacusia, retinopatía pigmentaria

B: Púrpura, esplenomegalia, microcefalia, retardo mental, meningoencefalitis, radioluscencia ósea, ictericia que inicia en las primeras 24 h de vida

\section{Caso confirmado por laboratorio}

Lactante con anticuerpos $\operatorname{lgM}(+)$ a virus rubéola que tiene confirmación clínica del síndrome

\section{Infección congénita por rubéola}

Lactante con anticuerpos lgM (+) a rubéola que no tiene clínica confirmada del síndrome

Ref: World Health Organization. Surveillance guidelines for measles and congenital rubella infection in the WHO European Region. Copenhagen: World Health Organization; 2003. 
infecta a mujeres embarazadas susceptibles en el primer trimestre del embarazo.

La gravedad del cuadro está estrechamente relacionada con las semanas de gestación. Si la infección se produce en las primeras ocho semanas de embarazo, el riesgo de SRC es de $85-95 \%$; entre 9 y 12 semanas se reduce a $52 \%$; entre 13 y 20 semanas a $16 \%$ y con 20 o más semanas de gestación su incidencia es indeterminada ${ }^{5,39}$.

\section{Síndrome de rubéola congénita}

La infección crónica, por ausencia de respuesta inflamatoria y la inhibición de la multiplicación celular en el feto en desarrollo -se cree que retarda la división celular- induce apoptosis y produce necrosis tisular, lo que puede llevar a aborto espontáneo, mortinato y SRC. Los defectos más frecuentes en este síndrome son las anomalías cardíacas ( $71 \%$ de los casos) y de ellas, $72 \%$ corresponden a ductus arterioso persistente, agregándose defectos del tabique interauricular o interventricular o estenosis de la arteria pulmonar. Otras manifestaciones son RCIU, microcefalia, hipoacusia sensorio neural, bajo peso de nacimiento, cataratas congénita, hipoplasia del iris, microftalmos y retinopatía visualizada "en sal y pimienta" (Tabla 11).

La rubéola congénita es una enfermedad progresiva por persistencia de la infección viral y deficiencias en respuesta inmune, que puede progresar hasta los dos años de vida. Cincuenta a $70 \%$ de los niños con infección congénita por rubéola pueden aparecer como aparentemente normales en el momento del nacimiento. Además pueden identificarse alteraciones transitorias como hepato-esplenomegalia, meningo-encefalitis, trombocitopenia, con o sin púrpura, y radioluscencia ósea ${ }^{5,39,40}$.

Los últimos casos de SRC confirmados en el país corresponden a 18 casos el año 2000 (genotipo 1E) y tres casos el 2007. Por ello, resulta relevante que al diagnosticar rubéola en una mujer embarazada, el caso debe seguirse hasta el nacimiento para la evaluación en el RN y estudio de $\mathrm{SRC}^{41}$.

Tabla 11. Hallazgos patológicos en el síndrome de rubéola congénita

\section{Localización anatómica o sistema \\ Hallazgos macro o microscópicos}

Placenta

Sistema nervioso central

Ojos

Oídos

Cardiovascular

Pulmonar

Hígado

Piel

Hueso

Músculo

Dientes

Hematológico

Inmunológico

Necrosis del esmalte en linfonodos
Infiltrado perivascular mononuclear en las deciduas. Edema, fibrosis y necrosis de vellosidades

Meningitis crónica con infiltrados de mononucleares, linfocitos y células plasmáticas en leptomeninges. Degeneración vascular, lesiones isquémicas y retardo en la mielinización cerebral

Cataratas, licuefacción cortical, necrosis del cuerpo ciliar, irido-ciclitis, atrofia del iris y defectos en pigmentación. Alteraciones en pigmentación retina. Arqueo posterior del nervio óptico

Hemorragia en cóclea fetal con resultado de necrosis epitelial. Infiltrado inflamatorio en la estría vascularis. Adhesión entre la membrana de Reissner y la membrana tectorial, atrofia del órgano de Corti, colapso y degeneración del sacculus

Frecuentes defectos cardíacos: ductus arterioso persistente, estenosis arteria pulmonar, defecto septales atriales y/o ventriculares. Miocarditis, pérdida de la estriación en células musculares, necrosis de la íntima de arterias mayores

Neumonía crónica intersticial con infiltrado mononuclear, linfocitos y células plasmáticas

Hialinización e hinchazón de hepatocitos, hematopoyesis, presencia de células gigantes multinucleadas

Lesiones purpúricas, áreas focales de eritropoyesis en dermis. Exantema reticulado crónico, signos de inflamación aguda y crónica, presencia de histiocitos en el dermis, edema

Adelgazamiento del trabeculado metafisial y descenso en el número de osteoblastos y osteoclastos. Predominio de células plasmáticas en las metáfisis y epífisis cartilaginosas y alrededor de los vasos. Adelgazamiento del cartílago

Anormalidades focales, pequeñas fibras con manchas oscuras, grupos musculares con menor tejido conectivo

Trombocitopenia transitoria con descenso de megacariocitos en la médula ósea, aumento de adhesividad plaquetaria. Histiocitosis

Fibrosis esplénica, pérdida arquitectura normal de linfonodos con ausencia de centro germinal. Disgamaglobulinemia, usualmente con descenso de $\lg G$ e $\lg A$ y aumento de $\lg M$

Ref: J. Cherry. Capítulo 173: Measles virus, en Feigin and Cherry`s Textbook of Pediatric Infectious Diseases, $7^{\circ}$ edition, Elsevier Saunders $2014 ; 2195-225$ 


\section{Diagnóstico}

\section{Mujer embarazada}

Además de evaluar el contacto epidemiológico y aspectos clínicos (generalmente inespecíficos), se le debe efectuar serología: IgG e IgM específicas. Esta última es positiva después de tres días de iniciado el exantema y perdura por ocho semanas; la IgG aparece desde la segunda semana. Si ambas pruebas resultan negativas, se sugiere una segunda muestra para el mismo análisis serológico a tres semanas del contagio. De iniciarse el estudio pasadas dos semanas de aparecido el exantema, se sugiere realizar un similar estudio serológico y complementado con test de avidez para $\operatorname{IgG}^{42}$.

En el país, un caso sospechoso se confirma por laboratorio en el ISP, a través de la detección de anticuerpos IgM específicos contra rubéola, por técnica de ELISA. En dos muestras serológicas, obtenidas con un intervalo de dos a tres semanas, se comprobará un aumento significativo de la concentración de anticuerpos IgG específicos contra virus rubéola. Otra manera de certificar el diagnóstico es por nexo epidemiológico, entendido como el antecedente de contacto con un caso confirmado de rubéola. El estudio debe incluir siempre una muestra de aspirado nasofaríngeo (ANF) para aislamiento viral y genotipificación, la que será procesada sólo en casos de lograrse la confirmación serológica $^{43}$.

\section{Recién nacido}

El diagnóstico se realiza por la determinación de $\operatorname{IgM}$ específica en sangre o por la demostración de IgG sérica persistente entre los seis y 12 meses de vida. Adicionalmente, para confirmar la infección, puede realizarse RPC en ANF, orina, LCR y sangre hasta el año de vida ${ }^{44}$.

Según establece la normativa nacional, para el estudio en RN se debe enviar al ISP una muestra de suero. En caso de resultar positiva para IgM rubéola, se solicitará una muestra de suero en la madre (posterior al parto) para estudio de IgG. Sólo en el caso de resultar positiva la muestra serológica del RN, se le solicitará una muestra respiratoria (ANF) para aislamiento viral ${ }^{43}$.

Dada la variabilidad de algunos métodos de laboratorio, resulta relevante que siempre las pruebas diagnósticas debieran ser validadas por un laboratorio de referencia.

\section{Tratamiento}

No existe tratamiento disponible para la madre durante la infección aguda ni para el RN infectado por lo que todos los esfuerzos terapéuticos deben estar puestos en la profilaxis con vacuna durante la infancia y durante las campañas periódicas de vacunación realizadas para tal efecto.

\section{Infección por citomegalovirus}

Citomegalovirus (CMV), es un virus ADN, ubicuo, de la familia Herpesviridae y específico del ser humano ${ }^{45}$. Es el principal agente causal de infección congénita y la primera causa de hipoacusia neuro-sensorial (HNS) no genética y de retardo mental (RM) adquirido en la infancia. Pese a lo anterior, la HNS congénita sin otras anomalías clínicas, rara vez se diagnostica como relacionada con el $\mathrm{CMV}$ en la primera infancia ${ }^{46,47}$. Es incluso más frecuente que la mayoría de los defectos de nacimiento (síndrome de Down y espina bífida) y de las condiciones congénitas evaluadas en el tamizaje a los RN, realizado en Estados Unidos de América (E.U.A.) y Europa ${ }^{48-50}$, convirtiéndose, por ende, en la causa más común de infección congénita y afecta a $0,5-2 \%$ de todos $\operatorname{los} \mathrm{RN}^{48}$.

\section{Epidemiología}

La incidencia de la transmisión congénita por CMV está muy determinada por la seroprevalencia de CMV en mujeres en edad fértil. Estudios prospectivos de mujeres embarazadas indican que la tasa de adquisición de CMV es de $2 \%$ anual en el nivel socioeconómico (NSE) medio-alto y $6 \%$ en los NSE más bajos ${ }^{51}$. En Chile, la seroprevalencia materna de CMV fue de $98 \%$ en $1978^{52}$ y actualmente este cifra es de $90 \%$ en mujeres embarazadas de NSE bajo y 50\% en NSE alto (Masami y Prado, comunicación personal 2009).

Los estudios han demostrado que existe transmisión de la infección materna al feto, tanto en la primo-infección (30-40\%), como en la re-infección o reactivación (1$2 \%)^{48,53}$, poniendo en evidencia que la inmunidad materna pre-existente no previene la transmisión intrauterina o el desarrollo de la enfermedad ${ }^{54-56}$. La incidencia de la infección congénita por CMV es alta, tanto en poblaciones con baja como con alta seroprevalencia poblacional. Sin embargo, los déficits neurológicos y el resultado de la enfermedad fetal más grave son más comunes después de la infección primaria materna, lo que ocurre habitualmente en poblaciones con menor seroprevalencia ${ }^{49,54}$. El riesgo de la transmisión vertical de CMV se incrementa con el avance de la gestación, pero el riesgo de complicaciones fetales/neonatales es inversamente proporcional a la edad gestacional de la infección ${ }^{57}$.

La infección afecta, en promedio, a $1 \%$ de todos los RN, siendo variable según la población estudiada. En Chile la tasa de infección congénita por CMV fue de $1,7 \%$ en 1978 , no existiendo nuevos registros al respecto $^{52,58}$

Entre 10 y $15 \%$ de los niños infectados congénitamente son sintomáticos al nacer, de los cuales $35 \%$ tienen HNS, hasta dos tercios tienen déficits neurológicos y $4 \%$ muere durante el período neonatal ${ }^{48,59}$. Estos niños desarrollarán también, en 90-95\% de los casos, alguna secuela neuro- 
lógica a largo plazo: HNS (58\%), RM (55\%), parálisis cerebral $(12 \%)$ y defectos visuales $(22 \%)$ entre otros ${ }^{53,60}$. Igualmente, los niños asintomáticos $(90 \%)$ desarrollarán HNS (6-23\%), microcefalia (2\%), RM (4\%) y corioretinitis $(2,5 \%)$, durante los primeros dos años de vida $(17-23)^{48}$; en ellos, la pérdida de audición es progresiva en $50 \%$, bilateral en $50 \%$ y de aparición tardía en $20 \%$ de los casos. La progresión se pesquisa en promedio a los 18 meses de vida y la presentación tardía puede manifestarse hasta los 6-7 años de edad ${ }^{48,68}$ (Figura 7).

El compromiso del SNC se asocia a pérdida progresiva de la audición, RDSM, epilepsia, parálisis cerebral y alteraciones visuales, en porcentajes no bien definidos. El cerebro del feto es especialmente vulnerable a las lesiones causadas por CMV a raíz de la citotoxicidad directa, inflamación y activación de las células de la microglia, siendo uno de los rasgos más característicos de la infección por CMV la ecogenicidad periventricular que evoluciona posteriormente a quistes del cuerno occipital ${ }^{57}$. La causa del RDSM se cree se debe a la sensibilidad de las células del SNC en crecimiento por los efectos apoptóticos y líticos del CMV, llevando a un daño estructural que puede o no ser visible en estudios de neuroimagen ${ }^{69}$.

La HNS asociada a la infección por CMV se debería a un daño coclear y del sistema vestibular, secundario a la replicación viral y respuesta inmune a la infección ${ }^{70,71}$. La HNS puede presentarse al momento del parto o en forma tardía, y su gravedad varía desde pérdida de la audición unilateral a frecuencias altas hasta sordera profunda bilateral, siendo frecuentes la progresión y la fluctuación de la enfermedad. Debido a que la HNS es la secuela más

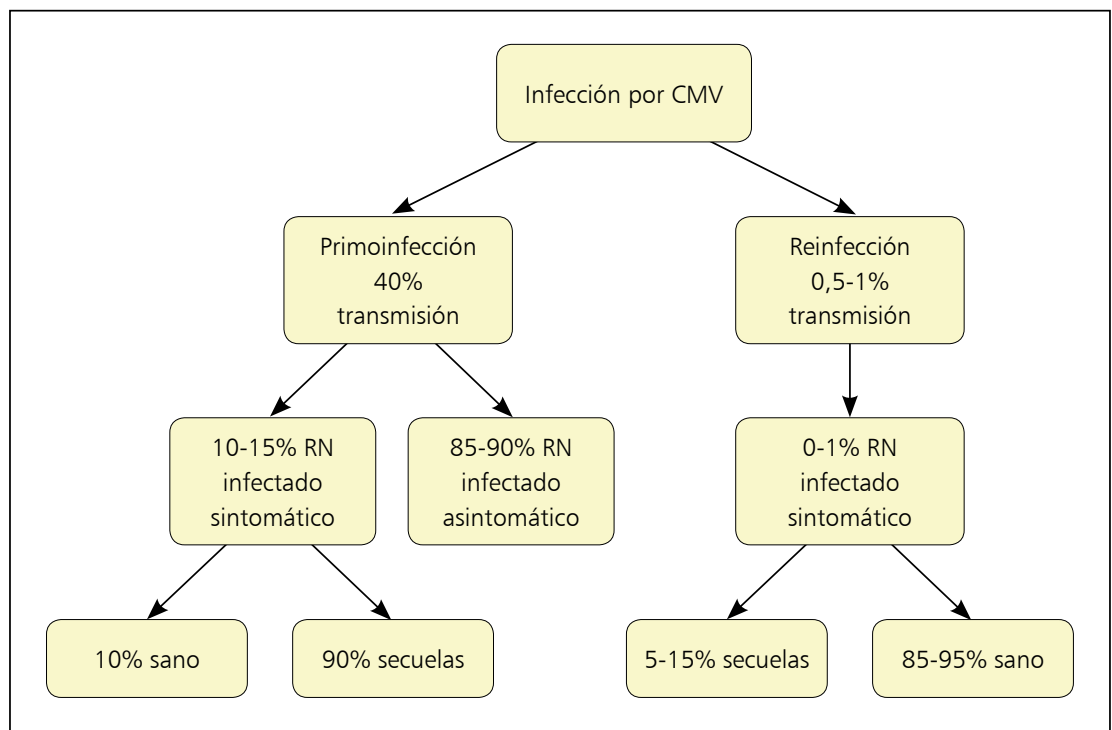

Figura 7. Riesgo de infección congénita por citomegalovirus en la mujer embarazada. Reproducido de: D.E. Soper. Congenital cytomegalovirus infection: An obstetrician's point of view. Clin Infect Dis 2013; 57 (S4): S171-3 frecuente de la infección congénita por CMV, representa $25 \%$ de todos los casos de sordera infantil en E.U.A., resultando en la mayor causa de discapacidad pediátrica a largo plazo $^{48}$. Su identificación temprana toma relevancia debido a lo potencialmente tratable de la $\mathrm{HNS}^{47}$.

\section{Diagnóstico}

\section{Mujer embarazada}

No existe hasta ahora consenso en realizar tamizaje universal para la detección de CMV en el embarazo, debido a la falta de una terapia que haya demostrado efectivamente la prevención de la infección congénita; en muchos países europeos en casos de infección demostrada se ofrece el aborto terapéutico ${ }^{48,72,73}$.

Distinguir entre la infección primaria y la re-infección o reactivación es difícil debido a que la IgM es detectable en menos de $30 \%$ de las mujeres con una infección primaria y puede persistir incluso hasta 12 meses después de la primo infección ${ }^{48}$. La detección de IgG puede traducir exposición previa al embarazo o puede aumentar producto de una re-infección con una nueva cepa de CMV o reactivación del virus latente durante el embarazo. La detección de avidez de IgG, una medida de la madurez de anticuerpos, mejora la capacidad de identificar la infección primaria; en caso de existir detección de IgM e IgG combinada con baja avidez de IgG sugiere una infección primaria por CMV ocurrida en los últimos 3-4 meses ${ }^{48}$.

\section{Feto}

Debido a que el feto comienza a excretar orina al líquido amniótico a partir de las semanas 19-20, considerando además que deben haber transcurrido al menos siete semanas desde la fecha probable de infección materna, se puede y recomienda realizar una amniocentesis a partir de la semana 21 de gestación para obtener una mejor sensibilidad. El cultivo viral del líquido amniótico presenta muchos falsos negativos y no está disponible habitualmente por lo que la RPC del líquido amniótico sería el mejor método diagnóstico por su buena sensibilidad (90-98\%) y especificidad (92-98\%) ${ }^{72}$.

Lo anterior debe acompañarse de seguimiento ecográfico seriado y estricto en búsqueda de hallazgos sospechosos de la afectación fetal. Algunos hallazgos indicativos de infección son: oligohidramnios o polihidramnios, hidrops fetal, RCIU, hepato-esplenomegalia, calcificaciones intrahepáticas, aumento de la ecogenicidad intestinal, microcefalia, dilatación ventricular, atrofia cortical y calcificaciones intracraneales. Otros hallazgos que tendrían mejor visualización a través de una RM fetal serían: presencia de polimicrogiria, hipoplasia cerebelosa o alteraciones en la sustancia blanca. Lamentablemente, todos estos hallazgos no se logran identificar en más de $30 \%$ de los $\operatorname{casos}^{72}$. 


\section{Recién nacido}

La sospecha clínica se establece en base a los antecedentes prenatales, lo cual muchas veces no ocurre en nuestro medio enfrentándonos por ende, al diagnóstico en un paciente RN. Los RN infectados pueden presentar al nacer diversa sintomatología aguda y no aguda como: trombocitopenia, hepatitis, hepato-esplenomegalia, hipoacusia neuro-sensorial, corio-retinitis, microcefalia, calcificaciones cerebrales, etc. ${ }^{46,48}$.

El diagnóstico se realiza con la detección de CMV en cultivos acelerados (shell vial) de muestras de orina y saliva ya que éstas presentan altas y constantes concentraciones de CMV. Las muestras deben ser obtenidas durante las primeras dos o tres semanas de vida ${ }^{52,73}$ ), debido a que, la excreción viral después de ese plazo puede reflejar una infección adquirida en forma postnatal (canal del parto o leche materna). En los últimos años, los métodos de detección rápida como la RPC, han demostrado ser extremadamente sensibles en diferentes muestras ${ }^{52,74-77}$ y comparables a los cultivos. La RPC para CMV en muestras de sangre almacenada en papel filtro prometió ser un buen método de detección ${ }^{77}$; sin embargo, un reciente estudio a gran escala demostró que la RPC en papel filtro tuvo falla para identificar la mayoría de los CMV, obteniéndose una sensibilidad aproximada de $30 \%$ comparándola con muestras de cultivo en saliva ${ }^{79}$. Otro estudio más reciente realizó la detección de CMV mediante RPC en saliva en casi 35 mil RN, comparando esta técnica con cultivo para CMV en saliva y orina. Este estudio prospectivo determinó que la utilización de RPC en tiempo real en muestras de saliva líquida y seca logró una sensibilidad > 97\% y especificidad $99,9 \%$ al compararla con muestras de orina ${ }^{80}$. Dos recientes estudios confirman la superioridad de la RPC por sobre el cultivo en muestras de orina estableciendo una sensibilidad sobre $95 \%$, incluso en muestra de orina obtenida de pañales (la sensibilidad del cultivo es de $55 \%)^{82,83}$. El diagnóstico no debe basarse en RPC de sangre, ya que la viremia es oscilante y pudiesen obtenerse falsos negativos con mayor frecuencia.

Como parte complementaria de la evaluación general del paciente, se deben incluir algunos exámenes de laboratorio como: recuento hematológico, pruebas hepáticas, función renal y RPC cuantitativa en sangre. En algunos países, sobre todo europeos, se estudia el LCR con el fin de verificar alteraciones en el análisis citoquímico y la replicación viral mediante RPC cuantitativa de $\mathrm{CMV}^{73}$.

\section{Tratamiento}

Debido a que las complicaciones auditivas y neurológicas asociadas a CMV continúan desarrollándose a lo largo de los primeros dos años de vida en pacientes infectados in utero, la supresión de la replicación de CMV puede prevenir o mejorar algunas de estas secuelas. Hasta ahora los grupos de expertos sólo recomiendan el tratamiento del CMV congénito sintomático con compromiso del SNC o compromiso órgano-específico (neumonía, hepatitis, hepato/esplenomegalia, trombocitopenia grave y/o persistente y compromiso multisistémico) antes de 30 días de vida ${ }^{73}$. Hace varios años, el Grupo Colaborativo Antiviral estableció que el tratamiento por seis semanas con ganciclovir intravenoso (6 mg/kg/dosis cada $12 \mathrm{~h}$ ), mostró una clara mejoría en el outcome de audición total a los seis meses, no evidenciándose deterioro alguno de la audición, en comparación al grupo control, que tuvo deterioro de $41 \%$ de la audición a los seis meses, lo cual fue estadísticamente significativo $(\mathrm{p}<0,01)$. Al año de edad, $21 \%$ de los que recibieron ganciclovir tenían deterioro de la audición en el mejor oído, en comparación con $68 \%$ de los controles, siendo esto también significativo $(\mathrm{p}<0,01)^{84}$. En lo que respecta al desarrollo neurológico los niños con CMV congénito sintomático con compromiso del SNC, que reciben la terapia con ganciclovir endovenoso, tienen menos retraso en el desarrollo a los seis y 12 meses, en comparación con los niños no tratados $(\mathrm{p}=0,02$ y 0,007 , respectivamente), siendo más marcado a los 12 meses $^{85}$.

El mayor efecto adverso fue la neutropenia, un efecto secundario conocido de este fármaco, que se produjo en dos terceras partes de los $\mathrm{RN}^{84}$. El mismo grupo realizó posteriormente un estudio farmacocinético que confirmó que valganciclovir oral, una pro droga de ganciclovir, en neonatos con CMV congénito sintomático (en dosis de 16 $\mathrm{mg} / \mathrm{kg} /$ dosis cada $12 \mathrm{~h}$ ) alcanzó concentraciones plasmáticas y en LCR similares a ganciclovir teniendo un perfil de efectos secundarios equivalentes y proporcionando así una opción práctica oral para el tratamiento de la enfermedad por CMV congénita ${ }^{86}$. La última publicación de este grupo con respecto a valganciclovir oral, fue su uso durante seis meses en comparación con el uso clásico de ganciclovir endovenoso por seis semanas observándose significativamente mejoría de la audición total a los 12 y 24 meses de vida y mejoría del neurodesarrollo (cognitivo, lenguaje y motor) también a los 12 y 24 meses en el grupo que usó valganciclovir por seis meses. Por otra parte, la incidencia de neutropenia fue similar en los grupos tratados con placebo y valganciclovir entre seis semanas y seis meses, lo que sugiere que la neutropenia en los bebés tratados con valganciclovir puede ser, al menos en parte, atribuible a la infección viral ${ }^{61}$. Por lo tanto, los niños con infección congénita por CMV que muestran secuelas neurológicas asociadas a CMV deben recibir tratamiento con valganciclovir y tener controles hematológicos, función renal y pruebas hepáticas, al menos semanales, las primeras seis semanas de tratamiento ${ }^{48,61}$.

Pese a que entre 10 y $20 \%$ de los niños asintomáticos pueden desarrollar secuelas como HNS tardía, se necesitan aún más estudios para determinar si estos pacientes se 
Tabla 12. Recomendaciones del CDC, Atlanta, E.U.A., para la prevención de la infección por citomegalovirus en la mujer embarazada

Lave sus manos con agua y jabón por 15-20 seg, especialmente luego de cambiar pañales, alimentar, sonar la nariz o manipular juguetes de niños pequeños

No comparta comida, bebidas o cubiertos con niños pequeños

No ponga el chupete de su hijo en la boca de la mujer embarazada

No comparta cepillos de dientes con niños pequeños

Evite el contacto con la saliva al besar niños

Limpie juguetes, mudadores u otras superficies que estén en contacto con orina o saliva de niños

Ref: 48 .

beneficiarían con el tratamiento antiviral y no existen recomendaciones de los expertos para su $\mathrm{uso}^{48}$.

\section{Prevención}

Inmunoglobulina hiperinmune contra $C M V\left(C y\right.$ togam $\left.{ }^{\circledR}\right)$

Los resultados de un estudio retrospectivo inicial realizado por Nigro y cols. ${ }^{87}$, fueron prometedores respecto al uso de inmunoglobulina contra CMV. Revello y cols., completaron recientemente un estudio de 124 mujeres embarazadas con infección primaria por CMV documentada para recibir placebo o inmunoglobulina contra CMV en forma mensual, desde el diagnóstico de la infección hasta la resolución del embarazo; sin embargo, los resultados no fueron estadísticamente significativos para apoyar el uso de la inmunoglobulina contra CMV durante el embarazo ${ }^{87}$, por lo cual no existe aún evidencia fundamentada para recomendarla. Actualmente están en curso estudios prospectivos, de los cuales aún no hay resultados publicados.

\section{Vacunas}

Múltiples ensayos se han realizado desde la década de los 70, pero hasta ahora no existe la formulación adecuada que logre la eficacia esperada y se está a la espera de ensayos en fase 3 que puedan dar mejores resultados ${ }^{48}$.

Debido a que aún no hay vacunación disponible y las opciones de tratamiento antenatal son limitadas, la prevención y/o reducción de CMV congénito debe centrarse en las medidas educativas y de higiene para todas las mujeres en edad fértil. Las mujeres con mayor riesgo de primo-infección incluyen a aquellas en edad fértil como: trabajadoras al cuidado de niños, trabajadoras de la salud en contacto con niños y mujeres con niños pequeños en su hogar. Todas las mujeres en edad fértil, independientemente de la presencia o ausencia de factores de riesgo, deben ser aconsejadas para reducir el riesgo de adquisición de CMV mediante prácticas de una higiene de manos adecuada y evitando el contacto con fluidos (saliva, orina) de niños, especialmente con aquellos bajo 36 meses $^{48,89}$ (Tabla 12).

Recientemente, en relación a este tema, Revello y cols realizaron un ensayo controlado prospectivo, que proporcionó evidencia acerca de que la intervención basada en la educación continua a mujeres embarazadas seronegativas para CMV, basado en el correcto lavado de manos y el manejo de fluidos corporales, logró prevenir en forma significativa la infección materna. A la espera de que la vacuna contra CMV esté disponible, la intervención descrita puede representar una estrategia responsable y aceptable de prevención primaria para reducir el riesgo potencial de infección por CMV congénita ${ }^{89}$.

\section{Herpes simplex}

Los virus herpes simplex (VHS) 1 y 2 pertenecen a la familia Herpesviridae. Son virus con un ADN de doble hebra, recubiertos por una nucleocápside icosaédrica; estructuralmente son prácticamente indistinguibles entre sí. El hombre es el único reservorio natural conocido ${ }^{90-94}$.

Se contagia desde un individuo con lesiones en la piel o mucosas o durante su excreción asintomática a través de la saliva (VHS-1), el semen o secreción vaginal (VHS-2). $\mathrm{Si}$ el contacto es directo, la mayoría de las personas se infectan de manera asintomática ${ }^{90}$. Los factores de riesgo para la adquisición genital del virus son: sexo femenino, bajo nivel socio-económico, historia previa de otras infecciones genitales, número de parejas sexuales ${ }^{94}$.

Tiene la capacidad de permanecer latente en el ganglio sensitivo del hospedero de por vida y puede reactivarse periódicamente y viajar por el axón hasta el sitio inicial de la infección o cerca de éste, resultando en una recurrencia clínica con lesiones evidentes o en una excreción asintomática del virus por las secreciones ${ }^{90,91}$.

\section{Epidemiología}

La infección neonatal por VHS es infrecuente con una incidencia estimada de 1:3.000-1: $20.000 \mathrm{RN}$ vivos y puede darse frente a la infección sintomática y la excreción asintomática materna ${ }^{94-97}$

La primo-infección se refiere a la adquisición de la infección por VHS-1 o VHS-2 sin exposición previa y sin formación previa de anticuerpos. La infección no primaria se refiere a la adquisición de infección por VHS-2 en un individuo con anticuerpos previos para VHS-1 o viceversa. La reactivación se refiere al aislamiento del mismo tipo viral en las lesiones genitales con anticuerpos formados previamente $\mathrm{e}^{92,93,95}$.

Las infecciones recurrentes son la forma clínica de presentación más frecuente durante el embarazo y de ellas 
2/3 son asintomáticas o presentan síntomas no sugerentes de infección herpética. Sin embargo, aquellos RN nacidos de madres que cursan con una primo-infección por VHS cercana al término del embarazo y que excretan el virus al momento del parto tienen un riesgo mayor (57\%) de desarrollar la infección que aquellos $\mathrm{RN}$ hijos de madre con re-infección por otro VHS $(25 \%)$ y que RN hijos de madre con infección recurrente $(2 \%)^{92-95,97}$.

\section{Cuadro clínico}

La infección en el $\mathrm{RN}$ se adquiere por tres vías diferentes: in utero (intrauterina), intraparto (perinatal) o postparto (postnatal); $85 \%$ de los RN se infecta por la vía intraparto, $10 \%$ por la vía postnatal y sólo $5 \%$ in utero $^{92,93,95}$ (Tabla 13).

La infección in utero es extremadamente inusual con una incidencia de 1:300.000 partos. Los $\mathrm{RN}$ infectados presentan hallazgos clínicos dermatológicos: cicatrices, rash (Figura 8), aplasia cutis, hiperpigmentación o hipo pigmentación; hallazgos oftalmológicos: microftalmia, corio-retinitis, atrofia óptica y hallazgos neurológicos: calcificaciones intracraneales, microcefalia y encefalomalacia $^{92-94}$.

Las infecciones adquiridas intraparto o postparto se pueden presentar clínicamente como enfermedad diseminada, con o sin compromiso del SNC, encefalitis herpética o enfermedad de piel-ojo-boca ${ }^{95,96}$. De manera global, aproximadamente $50 \%$ de las infecciones por VHS neonatal cursan con compromiso del SNC (encefalitis y/o enfermedad diseminada con compromiso de SNC) y $70 \%$ tienen lesiones vesiculares características en la piel $^{12,93,95,96}$ (Tabla 14).

\section{Infección diseminada (ID)}

Da cuenta de $25 \%$ de las infecciones neonatales por VHS y $2 / 3$ de los RN afectados tiene concomitantemente compromiso de SNC. Se presenta a los 10-12 días de vida, con compromiso multisistémico incluyendo SNC, pulmones, hígado, glándula suprarrenal, piel, ojos y boca (Figura 9). Veinte por ciento de los RN infectados puede no presentar vesículas. Clínicamente se presenta como una sepsis viral incluyendo falla respiratoria, falla hepática

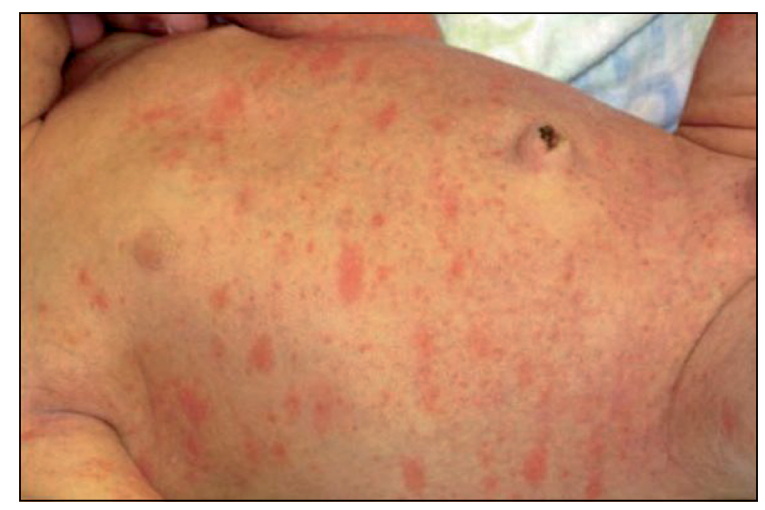

Figura 8. Herpes simplex diseminado. Erupción cutánea.
Tabla 13. Factores de riesgo para la transmisión de la infección por virus herpes simplex de la madre al hijo

- Tipo de infección materna: primaria vs recurrente

- Estado serológico contra VHS materno

- Duración de la rotura de membranas

- Integridad de las barreras muco-cutáneas, ej. Uso de electrodos en el cuero cabelludo del RN

- Vía del parto: cesárea vs parto vaginal

- Tipo de VHS: VHS-1 vs VHS-2

Refs. 92,94 y 95

\begin{tabular}{|c|c|c|c|}
\hline & Enfermedad diseminada & Enfermedad del SNC & Enfermedad piel-ojo-boca \\
\hline Modo de infección & Periparto/postparto & Periparto/postparto & Periparto/postparto \\
\hline Frecuencia & $25 \%$ & $30 \%$ & $45 \%$ \\
\hline Órganos comprometidos & $\begin{array}{l}\text { SNC, pulmón, hígado, glándula suprarrenal, } \\
\text { piel, ojo, membranas mucosas }\end{array}$ & SNC, con o sin compromiso de piel & Piel, ojos, membranas mucosas \\
\hline Presentación clínica & $\begin{array}{l}\text { Encefalitis, falla respiratoria, falla hepática, } \\
\text { CID, con o sin rash vesicular }\end{array}$ & $\begin{array}{l}\text { Convulsiones, letargia, irritabilidad, rechazo } \\
\text { alimentario, inestabilidad térmica con o sin } \\
\text { rash vesicular }\end{array}$ & Con o sin rash vesicular \\
\hline Mortalidad & $29 \%$ & $4 \%$ & ---- \\
\hline Desarrollo neurológico normal al año & $83 \%$ & $31 \%$ & $100 \%$ \\
\hline
\end{tabular}


y coagulación intravascular diseminada y la muerte se produce generalmente por coagulopatía grave y compromiso extenso hepático y pulmonar ${ }^{92,93}$. Aproximadamente la mitad de los $\mathrm{RN}$ con infección diseminada presentará recurrencias cutáneas ${ }^{96}$.

\section{Infección del sistema nervioso central}

Se da en 1/3 de las infecciones herpéticas neonatales y se presenta con compromiso cutáneo en $70 \%$ de los casos. La aparición es un poco más tardía, alrededor de los 16-19 días de vida. En el compromiso del SNC los síntomas son inespecíficos y similares a una infección bacteriana grave y el estudio del LCR, si es muy precoz, puede ser normal o con poca actividad inflamatoria. El neurotropismo se expresa como rechazo alimentario, letargia, convulsiones, compromiso de conciencia y compromiso hemodinámico. Aunque la encefalitis herpética clásica compromete preferentemente el lóbulo temporal, en la infección neonatal el compromiso incluye múltiples áreas cerebrales. En ausencia de compromiso cutáneo el cuadro clínico es indistinguible de otras causas virales o bacterianas de sepsis neonatal. La mortalidad está dada por la destrucción cerebral extensa y la disfunción autonómica ${ }^{92,93,96}$.

\section{Infección de piel, ojo y boca}

Da cuenta de $45 \%$ de los casos de infección neonatal y se presenta a los 10-12 días de vida (Figura 9). La infección es limitada en extensión y $80 \%$ presenta rash vesicular en el examen físico ${ }^{92,93,97}$

\section{Diagnóstico}

El aislamiento de VHS o cultivo viral sigue siendo el método definitivo de diagnóstico de la infección por VHS neonatal; sin embargo, la detección de ADN de VHS es

Figura 9. Enfermedad piel-ojo-boca por herpes simplex. un método aceptable de forma rutinaria y hoy en día es el examen más utilizado. Los estudios serológicos no se recomiendan de forma rutinaria para fines de diagnóstico en las infecciones por VHS neonatal ${ }^{98}$.

Antes del inicio de la terapia con aciclovir parenteral empírico en un lactante con sospecha de infección por VHS neonatal, se sugiere obtener las siguientes muestras para procesar RPC de $\mathrm{VHS}^{98}$ :

- Hisopado de boca, nasofaringe, conjuntiva y ano.

- Muestra de la base de vesículas cutáneas destechadas.

- LCR.

- Sangre.

Adicionalmente se sugiere muestra de alanina aminotransferasa, ya que se ha visto que su elevación se asocia con una mayor mortalidad ${ }^{99,100}$.

El estándar de oro actual para el diagnóstico de encefalitis por VHS es la RPC en LCR; sin embargo, hay que considerar que los primeros tres días el rendimiento es menor llegando sólo a 70\% y éste aumenta hasta cerca de $100 \%$ si la muestra de LCR se obtiene entre el tercer y quinto día de evolución, por lo cual se sugiere repetir el análisis del LCR si antes resultó negativo en los primeros tres días de evolución ${ }^{101}$.

La obtención de una muestra de sangre para RPC para VHS puede ser útil para establecer un diagnóstico de la infección neonatal, especialmente en bebés que se presentan sin lesiones cutáneas. La muestra es positiva en la mayoría de los pacientes con infección por VHS neonatal, independientemente de su clasificación clínica y, por lo tanto, no debe utilizarse para determinar la extensión de la enfermedad o la duración apropiada del tratamiento $^{98,99,101}$. Esto es más relevante en el escenario de un lactante con enfermedad de piel, ojo y mucosas, en quienes la muestra en sangre también resultará positiva la mayoría de las veces. Pese a ello, sobre la base de los datos disponibles actualmente, este escenario no justificaría la reclasificación como enfermedad diseminada por VHS, ya que, en ausencia de cualquier evidencia de compromiso diseminado de varios sistemas, el ADN del VHS detectable en plasma mediante RPC por sí mismo, no es requisito para terapia intravenosa prolongada ${ }^{98,99}$.

Poco se sabe acerca de si la persistencia de la positividad de la RPC en sangre se correlaciona clínicamente con la no resolución de la enfermedad. La muestra en sangre puede permanecer positiva durante todo el curso del tratamiento antiviral, pero el significado clínico de esto es desconocido. En la actualidad, los ensayos en serie de RPC en sangre no se recomiendan para controlar la respuesta a la terapia ${ }^{98}$.

\section{Tratamiento}

La mayoría de las infecciones neonatales por VHS resultaban en una morbi-mortalidad elevada antes del uso 
de la terapia antiviral, y es así como, los niños con ID y con enfermedad del SNC tenían una mortalidad de 85 y $50 \%$, respectivamente ${ }^{102}$.

La terapia antiviral, inicialmente con vidarabina y posteriormente con aciclovir ( $30 \mathrm{mg} / \mathrm{kg} /$ día), se caracterizó por lograr la mejoría de la mortalidad para la ID a $50 \%$ con vidarabina y a $61 \%$ con aciclovir y para enfermedades del SNC la mortalidad se redujo a $14 \%$, tanto para vidarabina como para aciclovir ${ }^{102}$.

El uso de aciclovir ev, en dosis de $60 \mathrm{mg} / \mathrm{kg} /$ día, fraccionado cada $8 \mathrm{hr}$, ha logrado que la tasa de sobrevida al año de vida sea de $96 \%$ para la enfermedad diseminada y de $71 \%$ para la infección del SNC. Además ha demostrado mejorar los resultados del desarrollo neurológico en los niños con enfermedad diseminada, sin lograr evidenciarse una mejoría en los resultados neurológicos de los niños con enfermedad del $\mathrm{SNC}^{94}$.

El uso de la terapia supresora con aciclovir oral en dosis de $300 \mathrm{mg} / \mathrm{m}^{2} /$ dosis por tres veces al día, administrada por vía oral durante los seis meses posteriores al término del tratamiento endovenoso, demostró mejores resultados en el neurodesarrollo y menores recurrencias de lesiones en la piel en pacientes con ID y con enfermedad del SNC que recibieron la terapia. Gracias al uso de esta terapia supresora se ha logrado mejorar el resultado neurológico en aquellos pacientes con enfermedad del $\mathrm{SNC}^{103}$.

Por lo anterior mencionado, la recomendación actual para la infección neonatal por VHS es emplear aciclovir endovenoso en las dosis descritas, durante 14 días en caso de enfermedad de piel, ojo y mucosas y por un período mínimo de 21 días en caso de ID y enfermedad del SNC. Todos los niños con afectación del SNC deben tener una punción lumbar repetida al final de la terapia para documentar la cura virológica en el LCR. Si esta repetición de RPC muestra un resultado positivo al final de la terapia, el aciclovir debe ser continuado por al menos siete días más y hasta conseguir la negatividad de la RPC ${ }^{98,102}$. Con posterioridad al tratamiento endovenoso debe administrase terapia supresora con aciclovir oral, sólo en los casos de ID y enfermedad del SNC, ya que en ellos se ha visto un mayor beneficio ${ }^{98,102}$.

El recuento absoluto de neutrófilos (RAN) se debe seguir dos veces por semana en la terapia con aciclovir endovenoso y luego, con la terapia supresora (aciclovir oral), se recomienda controlar el RAN a las dos y cuatro semanas de su inicio y luego mensualmente durante los seis meses que dura la supresión antiviral ${ }^{98,102}$.

El reconocimiento precoz y el inicio oportuno de la terapia antiviral empírica son de gran valor en el tratamiento de las infecciones neonatales por VHS. Los mejores resultados se observan cuando se inicia la terapia antiviral apropiada antes del inicio de la replicación viral significativa dentro del SNC o difusión generalizada del virus por todo el organismo ${ }^{98}$.

\section{Prevención}

La cesárea ha probado ser efectiva en la prevención de la infección del RN en madres con lesiones genitales activas si se realiza al menos cuatro horas previo a la rotura de membranas, pero es importante tener en cuenta que se reportan casos de infección del RN pese a nacer por cesárea, dado probablemente por el tiempo de rotura de membranas, falta de indemnidad de las mucosas y la posibilidad de infección in utero ${ }^{92,93,97}$.

Actualmente el American College of Obstetricians and Gynecologists (ACOG) y la American Academy of Pediatrics (AAP) recomiendan la cesárea electiva como vía de parto en mujeres con lesiones genitales sugerentes de una infección herpética activa ${ }^{92-95,106}$.

\section{Resumen}

Existen numerosas infecciones bacterianas, virales y parasitarias que pueden transmitirse desde la madre al feto o recién nacido $(\mathrm{RN})$ y que significan un riesgo para él. El acrónimo TORCH se utiliza en forma universal para caracterizar a aquel feto o RN que presenta un cuadro clínico compatible con una infección congénita y que permite un enfrentamiento racional, tanto diagnóstico como terapéutico. El concepto tradicional de realizar un "test de TORCH" sin consideraciones específicas a cada paciente, hoy en día se considera no adecuado y ha sido reemplazado por exámenes específicos para patógenos específicos bajo circunstancias bien definidas. El presente documento revisa las características generales, epidemiológicas, patogénicas, diagnósticas y terapéuticas de los patógenos más frecuentemente involucrados en el estudio de pacientes con sospecha de TORCH.

\section{Referencias bibliográficas}

1.- Sampedro A, Aliaga L, Mazuelas P, Rodríguez-Granger J. Diagnóstico de infección congénita. Enferm Infecc

Microbiol Clin 2011; 29 (Supl 5): 15-20.

2.- Abarca K. Infecciones en la mujer embarazada transmisibles al feto. Rev Chilena Infectol 2003;
20 (Supl 1): S41-S46.

3.- Sánchez P, Demmler-Harrison G. Viral Infections of the Fetus and Neonate. En: Feigin R, Cherry J, Demmler-Harrison G, Kaplan S., eds. Feigin \& Cherry's Textbook of Pediatric Infectious Diseases. $6^{\text {th }}$ Edition. Philadelphia. Saunders Elsevier; 2009, p. 895-941.
4.- De Jong E, Vossen A C, Walther F J, Lopriore E. How to use neonatal TORCH testing. Arch Dis Child Educ Pract Ed 2013; 98: 93-8.

5.- Shet A. Congenital and perinatal infections: Throwing new light with an old TORCH. Indian J Pediatr 2011; 78: 88-95. 
6.- Van der Weiden S, De Jong E, Te Pas A, Middledorp J, Vossen A, Rijken M, et al. Is routine TORCH screening and urine $\mathrm{CMV}$ culture warranted in small for gestational age neonates? Early Hum Dev 2011; 87: 103-7.

7.- Yamamoto R, Ighii K, Shimada M, Hayashi S, Hidaka N, Nakayama M, et al. Significance of maternal screening for toxoplasmosis, rubella, cytomegalovirus and herpes simplex virus infection in cases of fetal growth restriction. J Obstet Gynaecol Res 2013; 39 (3): 653-7.

8.- Apt W. Infecciones por parásitos más frecuentes y su manejo. Rev Med Clin Condes 2014; 25 (3): 485-528.

9.- Durlach R, Kaufer F, Carral L, Freuler C, Ceriotto M, Rodrígez M, et al. Consenso argentino de toxoplasmosis congénita. Medicina (Buenos Aires) 2008; 68: 75-87.

10.- Remington J S, Mc Leod R, Wilson C B, Desmonts G. Toxoplasmosis. Remington J, Klein J, Wilson C, Nizet V, Maldonado Y, eds. Remington \& Klein's Infectious Diseases of the Fetus and Newborn Infant. 7th Edition. Philadelphia. Saunders Elsevier; 2011, p 918-1041.

11.- Baquero-Artigao F, del Castillo F, Fuentes I, Goncé-Fortuny C, Fernández-Miranda $\mathrm{M}$ de la C, et al. Guía de la Sociedad Española de Infectología Pediátrica para el diagnóstico y tratamiento de la toxoplasmosis congénita. An Pediatr (Barc) 2013; 79 (2): 116.e1-116.e16.

12.- Sampedro A. Aliaga L, Mazuelas P, Rodríguez Granger J. Diagnóstico de infección congénita. Enferm Infecc Microbiol Clin 2011; 29 (Supl 5): 15-20.

13.- Canales M, Navia F, Torres F, Concha M, Guzmán A, Pérez C, et al. Evaluación de un test comercial de avidez de IgG: aporte al diagnóstico de primo infección por Toxoplasma gondii. Rev Chilena Infectol 2010; 27 (6): 499-504.

14.- del Castillo F. Diagnóstico y tratamiento de la toxoplasmosis congénita. An Pediatr Contin 2005; 3 (2): 65-72.

15.- MINSAL, Norma Conjunta de Prevención de la Transmisión Vertical del VIH y Sífilis. Norma General Técnica No 0141 de 2012.

16.- Reyes A, Bustos M, Muñoz P. Características clínica, serológicas y seguimiento de binomios madre-hijo con sospecha de sífilis congénita en el Hospital Félix Bulnes Cerda. Evaluación de 6 años (2008-2014). XXXI Congreso Chileno de Infectología 2014, P-48.

17.- Hawkes S, Matin N, Brotet N, Low N. Effectiveness of interventions to improve screening for syphilis in pregnancy: a systematic review and meta-analysis. Lancet Infect Dis 2011; 11 (9): 684-91.

18.- Wendel G, Sheffield J, Hollier L, Hill J, Ramsey P, Sánchez P. Treatment of syphilis in pregnancy and prevention of congenital syphilis. Clin Infect Dis 2002; 35 (Suppl 2): S200-S209.
19.- Rac M, Bryant S, Cantey J, McIntire D. Maternal titer after adequate syphilotherapy during pregnancy. Clin Infect Dis 2015; 60: 123-5.

20.- Nathan L, Bohman V R, Sánchez P J, Leos N K, Twickler D M, Wendel GD Jr. In utero infection with Treponema pallidum in early pregnancy. Prenat Diagn 1997; 17: 119-23.

21.- Alexander J M, Sheffield J S, Sánchez P J, Mayfield J, Wendel G D Jr. Efficacy of treatment for syphilis in pregnancy. Obstet Gynecol 1999; 93: 5-8.

22.- Lukehart S A, Fohn M J, Baker-Zander S A. Efficacy of azithromycin for therapy of active syphilis in the rabbit model. J Antimicrob Chemother 1990; 25 (Suppl A): 91-9.

23.- Woods C R. Syphilis congenital and acquired. Sem Pediatric Infect Dis 2005; 16 : 245-57.

24.- Kollmann T R, Dobson S. Syphilis. In: Remington J S, Klein J O, Wilson C B, Nizet V, Maldonado Y A, eds. Remington \& Klein's Infectious Diseases of the Fetus and Newborn Infant, $7^{\text {th }}$ Ed. 2011. Philadelphia, Ed. Elsevier. pp 524-63.

25.- Shah M C, Barton L, Congenital syphilitic hepatitis. Pediatr Infect Dis J 1989; 8: 891-2.

26.- Thorley J D, Kaplan J M, Holmes R K, McCracken G H Jr, Sanford JP. Passive transfer of antibodies of maternal origin from blood to cerebrospinal fluid in infants. Lancet 1975; 1 : 651-3.

27.- Centers for Disease Control and Prevention (CDC). Sexually Transmitted Diseases Treatment Guidelines 2015. MMWR Morb Mortal Wkly Rep. Recomm Rep 2015; 64 (3): 1-137.

28.- Dobson S R, Sánchez P J. Syphilis. In: Feigin \& Cherry's Textbook of Pediatric Infectious Diseases. $7^{\text {th }}$ Ed. 2014. Elsevier, Saunders. Philadelphia, Pa. pp 1761-81.

29.- Miranda M C C, Rozenfeld S, Oliveira S P. Reações adversas não-alérgicas à suspensão injetável de benzilpenicilina benzatina: uma revisão sistemática. J Vasc Br 2004; 3 (3): 253-60.

30.- Reyes A, Chorbadjian G, Parada M A, Turris J, Bravo N, Araya CG. Sífilis congénita: Optimizando el diagnóstico en 191 neonatos de madres seropositivas (1994-1999). Rev Chilena Infectol 2004; 21 (4): 307-11.

31.- Murcia L, Carrilero B, Muñoz-Dávila M J, Thomas M C, López M, Segovia M. Risk factors and primary prevention of congenital Chagas disease in a nonendemic country. Clin Infect Dis 2013; 56: 496-502.

32.- MINSAL 2011. Protocolo de atención clínica de la enfermedad de Chagas. http://ivl.ispch. cl/_Documentos\%5CTrypanosoma\%5C Protocolo_Chagas.pdf
33.- MINSAL 2014. Norma general técnica. Control y Prevención Nacional de la Enfermedad de Chagas. http://web.minsal.cl/sites/default/files/ NORMA\%20TECNICA_CHAGAS_FINAL. pdf

34.- Carlier I, Truyens C. Congenital Chagas disease as an ecological model of interactions between Trypanosoma cruzi parasites, pregnant women, placenta and fetuses. Acta Tropica 2015; 151 : 103-15.

35.- Carlier I, Torrico F, Sosa-Estani S, Russomando G, Luquetti A, Freilij H, et al. Congenital Chagas disease: Recommendations for diagnosis, treatment and control of newborns, siblings and pregnant women. PLoS Negl Trop Dis 5 (10): e1250.

36.- Cevallos A M, Hernández R. Chagas disease: pregnancy and congenital transmission. Bio Med Res Intern 2014, Article ID 401864.

37.- Cucunuba Z, Valencia-Hernández C, Puerta C, Sosa-Estani S, Torrico F, Cortés J, et al. Primer Consenso Colombiano sobre Chagas congénito y orientación clínica a mujeres en edad fértil con diagnóstico de Chagas. Infectio 2014; 18 (2): 50-65.

38.- Avendaño L F, Ferrés M, Spencer E. Virología Clínica. Editorial Mediterráneo 2011, 181-4.

39.- http://epi.minsal.cl/rubeola-materialesrelacionados/

40.- Best J M. Rubella. Semin Fetal Neonatal Med 2007; 12 (3): 18292.

41.- Documentación para la verificación de la eliminación del sarampión, rubéola y síndrome de rubéola congénita. Gallego D. editora. MINSAL-OPS 2011. https://pftp.paho.org/ Public/FCH/IM/Elimination/Informes\%20 de\%20paises/OPS-FINAL29-12-2011-CHILE. pdf

42.- Vauloup-Fellous C, Bouthry E. Prescription et interprétation des bilans sérologiques dans le cadre d'infections maternelles à risque de transmission foetale. Presse Med 2015; 44: 621-30.

43.- Circular B51, $\mathrm{N}^{\circ} 27$ de julio de 2010: Actualización enfermedades eliminadas de América: vigilancia integrada sarampión (B05)rubéola (B06). Subsecretaría de Salud Pública, Departamento de Epidemiología, MINSAL Chile.

44.- Rajasundari T A, Sundaresan P, Vijayalakshmi P, Brown D W, Jin L. Laboratory confirmation of congenital rubella syndrome in infants: An Eye Hospital based investigation. J Med Virol 2008; 80: 536-46.

45.- Choudhary A, Pati S K, Patro R K, Deorari A K, Dar L. Comparison of conventional, immunological and molecular techniques for the diagnosis of symptomatic congenital human cytomegalovirus infection in neonates and infants. Indian J Med Microbiol 2015; 33 Suppl: 15-9. 
46.- Stagno S. Cytomegalovirus infection: a pediatrician's perspective. Curr Probl Pediatr 1986; 16: 629-67.

47.- Kawada J, Torii Y, Kawano Y, Suzuki M, Kamiya Y, Kotani T, et al. Viral load in children with congenital cytomegalovirus infection identified on newborn hearing screening. J Clin Virol 2015; 65: 41-5.

48.- Hamilton S T, van Zuylen W, Shand A, Scott G M, Naing Z, Hall B, et al. Prevention of congenital cytomegalovirus complications by maternal and neonatal treatments: a systematic review. Rev Med Virol 2014; 24: 420-33.

49.- Bialas K M, Swamy G K, Permar S R. Perinatal cytomegalovirus and varicella zoster virus infections: epidemiology, prevention and treatment. Clin Perinatol 2015; 42: 61-75.

50.- Gold E, Nankervis G A. Cytomegalovirus. In: Evans AS, ed. 1982 Viral Infections of Humans: Epidemiology and Control, New York: Plenum: 167-86.

51.- Krech U, Jung M, Jung F. Cytomegalovirus Infections of Man, 1971 Basel, Karger ed: 18-35.

52.- Stagno S, Pass R F, Cloud G, Britt W J, Henderson R E, Walton P D, et al. Primary cytomegalovirus infection in pregnancy: incidence, transmission to fetus and clinical outcome. JAMA 1986; 256: 1904-8.

53.- Stagno S, Pass R F, Dworsky M E, Alford C A Jr. Maternal cytomegalovirus infection and perinatal transmission. Clin Obstet Gynecol 1982; 25: 563-76.

54.- Fowler K B, Stagno S, Pass R F, Britt W J, Boll T J, Alford C A. The outcome of congenital cytomegalovirus infection in relation to maternal antibody status. N Engl J Med 1992; 326: 663-7.

55.- Boppana S B, Fowler K B, Britt W J, Stagno S, Pass R F. Symptomatic congenital cytomegalovirus infection in infants born to mothers with preexisting immunity to cytomegalovirus. Pediatrics 1999; 104 (1 Pt 1): 55-60.

56.- Boppana S B, Rivera L B, Fowler K B, Mach M, Britt W J. Intrauterine transmission of cytomegalovirus to infants of women with preconceptional immunity. N Engl J Med 2001; 344: 1366-71.

57.- Revello M G, Gerna G. Diagnosis and management of human cytomegalovirus infection in the mother, fetus, and newborn infant. Clin Microbiol Rev 2002; 15: 680-715.

58.- Hui L, Wood G. Perinatal outcome after maternal primary cytomegalovirus infection in the first trimester: a practical update and counseling aid. Prenat Diagn 2015; 35: 1-7.

59.- Perlman J M, Argyle C. Lethal cytomegalovirus infection in preterm infants: clinical, radiological, and neuropathological findings. Ann Neurol 1992; 31: 64-8.
60.- Kimberlin D W, Jester P M, Sánchez P J, Ahmed A, Arav-Boger R, Michaels M G, et al. Valganciclovir for symptomatic congenital cytomegalovirus disease. N Engl J Med 2015; 372: 933-43.

61.- Harris S, Ahlfors K, Ivarsson S, Lernmark B, Svanberg L. Congenital cytomegalovirus infection and sensorineural hearing loss. Ear Hear 1984; 5: 352-5.

62.- Williamson W D, Percy A K, Yow M D, Gerson P, Catlin F I, Koppelman M L, et al. Asymptomatic congenital cytomegalovirus infection. Audiologic, neuroradiologic and neurodevelopmental abnormalities during the first year. Am J Dis Child 1990; 144: 1365-8.

63.- Ivarsson S A, Lernmark B, Svanberg L. Tenyear clinical, developmental and intellectual follow up of children with congenital cytomegalovirus infection without neurologic symptoms at one year of age. Pediatrics 1997; 99: 800-3.

64.- Kashden J, Frison S, Fowler K, Pass R F, Boll T J. Intellectual assessment of children with asymptomatic congenital cytomegalovirus infection. J Dev Behav Pediatr 1998; 19: 254-9.

65.- Hicks T, Fowler K, Richardson M, Dahle A, Adams L, Pass R. Congenital cytomegalovirus infection and neonatal auditory screening. J Pediatr 1993; 123: 779-82.

66.- Spector S A, Merrill R, Wolf D, Dankner W M. Detection of human cytomegalovirus in plasma of AIDS patients during acute visceral disease by DNA amplification. J Clin Microbiol 1992; 30: 2359-65.

67.- Nelson C T, Istas A S, Wilkerson M K, Demmler G J. PCR detection of cytomegalovirus DNA in serum as a diagnostic test for congenital cytomegalovirus infection. J Clin Microbiol 1995; 33: 3317-8.

68.- Demmler G J, Buffone G J, Schimbor C M, May R A. Detection of cytomegalovirus in urine from newborns by using polymerase chain reaction DNA amplification. J Infect Dis 1988; 158: $1177-84$

69.- Johansson P J H, Jonsson M, Ahlfors K, Ivarsson S A, Svanberg L, Guthenberg C. Retrospective diagnosis of congenital cytomegalovirus infection performed by polymerase chain reaction in blood stored on filter paper. Scand J Infect Dis 1997; 29 : 465-8.

70.- Dahle A J, McCollister F P, Stagno S, Reynolds D W, Hoffman H E. Progressive hearing impairment in children with congenital cytomegalovirus infection. J Speech Hear Disord 1979; 44: 220-9.

71.- Stagno S, Reynolds D W, Amos C S, Dahle A J, McCollister F P, Mohindra I, et al. Auditory and visual defects resulting from symptomatic and subclinical congenital cytomegaloviral and toxoplasma infections. Pediatrics 1977; 59: 669-78.
72.- Nishida K, Morioka I, Nakamachi Y, Kobayashi Y, Imanishi T, Kawano S, et al. Neurological outcomes in symptomatic congenital cytomegalovirus-infected infants after introduction of newborn urine screening and antiviral treatment. Brain Dev 2016; 38: 209-16.

73.- Baquero-Artigao F. Grupo de estudio de la infección congénita por citomegalovirus de la Sociedad Española de Infectología Pediátrica. [Consensus document from the Spanish Society of Paediatric Infectious Diseases (SEIP) on the diagnosis and treatment of congenital cytomegalovirus infection]. An Pediatr (Barc) 2009; 71: 535-47.

74.- Griffiths P, Baraniak I, Reeves M. The pathogenesis of human cytomegalovirus. J Pathol 2015; 235: 288-97.

75.- Dzierzahowska D, Augustynowicz E, Gzyl A, Vogtt E, Milewska-Bobula B, Swiatkowska E, et al. Application of polymerase chain reaction (PCR) for the detection of DNA-HCMV in cerebrospinal fluid of neonates and infants with cytomegalovirus infection. Neurol Neurochir Pol 1997; 31: 447-62.

76.- Revello M G, Zavattoni M, Baldanti F, Sarasini A, Paolucci S, Gerna G. Diagnostic and prognostic value of human cytomegalovirus load and IgM antibody in blood of congenitally infected newborns. J Clin Virol 1999; 14: 57-66.

77.- Lanari M, Lazzarotto T, Venturi V, Papa I, Gabrielli L, Guerra B, et al. Neonatal cytomegalovirus blood load and risk of sequelae in symptomatic and asymptomatic congenitally infected newborns. Pediatrics 2006; 117 : e76-83.

78.- Barbi M, Binda S, Caroppo S, Primache V, Dido $\mathrm{P}$, et al. CMV gB genotypes and outcome of vertical transmission: study on dried blood spots of congenitally infected babies. J Clin Virol 2001; 21: 75-9.

79.- Manicklal S, Emery V C, Lazzarotto T, Boppana S B, Gupta R K. The "silent" global burden of congenital cytomegalovirus. Clin Microbiol Rev 2013; 26: 86-102.

80.- Boppana S B, Ross S A, Novak Z, Shimamura M, Tolan RW Jr, Palmer A L, et al. Dried blood spot real-time polymerase chain reaction assays to screen newborns for congenital cytomegalovirus infection. JAMA 2010; 303: 1375-82.

81.- Boppana S B, Ross S A, Shimamura M, Palmer A L, Ahmed A, Michaels MG, et al. Saliva polymerase-chain-reaction assay for cytomegalovirus screening in newborns. N Engl J Med 2011; 364: 2111-8.

82.- Pinninti S G, Ross S A, Shimamura M, Novak Z, Palmer A L, Ahmed A, et al. National Institute on Deafness and Other Communication Disorders CMV and Hearing Multicenter Screening (CHIMES) Study. Comparison 
of saliva PCR assay versus rapid culture for detection of congenital cytomegalovirus infection. Pediatr Infect Dis J 2015; 34 (5): 536-7.

83.- Ross S A, Ahmed A, Palmer A L, Michaels M G, Sánchez P J, Stewart A, et al. National Institute on Deafness and Other Communication Disorders CHIMES Study. Urine collection method for the diagnosis of congenital cytomegalovirus infection. Pediatr Infect Dis J. 2015; 34: 903-5.

84.- Kimberlin D W, Lin C Y, Sánchez P J, Demmler G J, Dankner W, Shelton M, et al. National Institute of Allergy and Infectious Diseases Collaborative Antiviral Study Group. Effect of ganciclovir therapy on hearing in symptomatic congenital cytomegalovirus disease involving the central nervous system: a randomized, controlled trial. J Pediatr 2003; 143: $16-25$.

85.- Oliver S E, Cloud G A, Sánchez P J, Demmler G J, Dankner W, Shelton M, et al. National Institute of Allergy, Infectious Diseases Collaborative Antiviral Study Group. Neurodevelopmental outcomes following ganciclovir therapy in symptomatic congenital cytomegalovirus infections involving the central nervous system. J Clin Virol 2009; 46 Suppl 4: S22-6.

86.- Kimberlin D W, Acosta E P, Sánchez P J, Sood S, Agrawal V, Homans J, et al. National Institute of Allergy and Infectious Diseases Collaborative Antiviral Study Group. Pharmacokinetic and pharmacodynamic assessment of oral valganciclovir in the treatment of symptomatic congenital cytomegalovirus disease. J Infect Dis 2008; 197: 836-45.

87.- Nigro G, Adler S P, La Torre R, Best A M. Congenital Cytomegalovirus Collaborating Group. Passive immunization during pregnancy for congenital cytomegalovirus infection. N Engl J Med 2005; 353: 1350-62.

88.- Revello M G, Lazzarotto T, Guerra B, Spinillo A, Ferrazzi E, Kustermann A, et al. CHIP Study Group. A randomized trial of hyperimmune globulin to prevent congenital cytomegalovirus. N Engl J Med 2014; 370 : 1316-26.

89.- Revello M G, Tibaldi C, Masuelli G, Frisina V, Sacchi A, Furione M. CCPE Study Group. Prevention of primary cytomegalovirus infection in pregnancy. EBio Medicine 2015; 2: 1205-10.

90.- Avendaño L. Cap 17: Virus Herpes. Avendaño L, Ferrés M, Spencer E. Virología Clínica, $1^{\mathrm{a}}$ Edición. Santiago. Ed. Mediterráneo 2011: 311-2.

91.- Gutiérrez K, Whitley R, Arvin A. Chapter 26: Herpes simplex virus infection. Remington J, Klein J, Wilson C, Nizet V, Maldonado Y., eds. In Remington \& Klein's Infectious Diseases of the Fetus and Newborn Infant, 7 Edition. Philadelphia, Ed. Elsevier 2011: 813-33.

92.- Pinninti S G, Kimberlin D W. Neonatal herpes simplex virus infections. Pediatr Clin North Am 2013; 60: 351-65.

93.- Pinninti S G, Kimberlin D W. Maternal and neonatal herpes simplex virus infections. Am J Perinatol 2013; 30: 113-20.

94.- James S H, Kimberlin D W. Neonatal herpes simplex virus infection. Epidemiology and treatment. Clin Perinatol 2015; 42: 47-59.

95.- Kimbelin D W, Baley J. Guidance on management of asymptomatic neonates born to women with active genital herpes lesions. Pediatrics 2013; 131: e635-46.

96.- Conca N, Labraña Y, Bercovich M, Cienfuegos G, Santolaya M E. Encefalitis herpética neonatal: dos gemelas, dos casos. Rev Chilena Infectol 2011; 28: 257-61.
97.- Kimberlin D W. Herpes simplex virus infections in neonates and early childhood. Sem Pediatr Infect Dis 2005; 16: 271-81.

98.- James S H, Kimberlin D W. Neonatal herpes simplex virus infection. Infect Dis Clin North Am 2015; 29: 391-400.

99.- Melvin A J, Mohan K M, Schiffer J T, Drolette L M, Magaret A, Corey L, et al. Plasma and cerebrospinal fluid herpes simplex virus levels at diagnosis and outcome of neonatal infection. J Pediatr 2015; 166: 827-33.

100.-American Academy of Pediatrics. Herpes simplex In Pickering L K, Baker C J, Kimberlin D W, Long S S, eds. Red Book. 2015. Report of the Committee on Infectious Diseases $30^{\text {th }}$ ed. Elk Grove Village, IUl. American Acaddemy of Pediatrics 2015; pp: 432-45.

101.-Lakeman F D, Whitley R J. Diagnosis of herpes simplex encephalitis: application of polymerase chain reaction to cerebrospinal fluid from brainbiopsied patients and correlation with disease. J Infect Dis 1995; 171: 857-63.

102.-James S H, Kimberlin D W. Quantitative herpes simplex virus concentrations in neonatal infection. J Pediatr 2015; 166: 793-5.

103.-Kimberlin D W, Lin C Y, Jacobs R F, Powell D A, Corey L, Gruber W C, et al. Safety and efficacy of high-dose intravenous acyclovir in the management of neonatal herpes simplex virus infections. Pediatrics 2001; 108 : 230-8.

104.-Kimberlin D W, Whitley R J, Wan W, Powell D A, Storch G, Ahmed A, et al. National Institude of Allergy and Infectious Diseases Collaborative Antiviral Study Group. Oral acyclovir suppression and neurodevelopment after neonatal herpes. N Engl J Med 2011; 365: 1284-92.

105.-Gardella C, Brown Z. Prevention of neonatal herpes. Br J Obstet Gynecol 2011; 118: 187-92. 